\title{
CART in the regulation of appetite and energy homeostasis
}

\section{Jackie Lau and Herbert Herzog*}

Neuroscience Division, Garvan Institute of Medical Research, Sydney, NSW, Australia

\section{Edited by:}

Nathalie Just, Centre d'Imagerie

Biomédicale, Switzerland

\section{Reviewed by:}

Jacques Epelbaum, Université Paris

Descartes, France

Denise D. Belsham, University of

Toronto, Canada

*Correspondence:

Herbert Herzog, Neuroscience

Division, Garvan Institute of Medical

Research, 384 Victoria Street,

Darlinghurst, Sydney, NSW 2010,

Australia

e-mail: h.herzog@garvan.org.au
The cocaine- and amphetamine-regulated transcript (CART) has been the subject of significant interest for over a decade. Work to decipher the detailed mechanism of CART function has been hampered by the lack of specific pharmacological tools like antagonists and the absence of a specific CART receptor(s). However, extensive research has been devoted to elucidate the role of the CART peptide and it is now evident that CART is a key neurotransmitter and hormone involved in the regulation of diverse biological processes, including food intake, maintenance of body weight, reward and addiction, stress response, psychostimulant effects and endocrine functions (Rogge et al., 2008; Subhedar et al., 2014). In this review, we focus on knowledge gained on CART's role in controlling appetite and energy homeostasis, and also address certain species differences between rodents and humans.

Keywords: CART, energy homeostasis, stress response, food intake, body weight

\section{INTRODUCTION}

Experiments conducted with acute administration of cocaine or amphetamine in rodents resulted in the upregulation of a particular mRNA species in the striatum of the brain that was subsequently named "cocaine- and amphetamine-regulated transcript" (CART) and the encoded peptides are referred to as CART peptides (Spiess et al., 1981; Douglass et al., 1995). Importantly, CART mRNA levels were also found increased in the nucleus accumbens on post-mortem tissues from human victims of cocaine overdose (Albertson et al., 2004). CART is transcribed as two alternatively spliced mRNAs that are of different lengths and hence produce pro-peptides of different lengths, called proCART 1-89 and proCART 1-102 (Douglass et al., 1995; Douglass and Daoud, 1996). However, the mRNA splicing has no effect on the final peptide, as the active parts of the CART peptides are encoded by a sequence that lies downstream of the spliced region and is therefore identical in both pro-peptides (Douglass et al., 1995; Dey et al., 2003). However, the proCART peptides contain several cleavage sites that allow post-translational processing by pro-hormone convertases in a tissue-specific manner (Seidah et al., 1991; Douglass et al., 1995; Douglass and Daoud, 1996; Dong et al., 1997; Koylu et al., 1997; Steiner, 1998; Kuhar and Yoho, 1999; Thim et al., 1999; Vrang et al., 1999a; Dun et al., 2000; Dey et al., 2003; Stein et al., 2006). This processing produces at least two known biologically active peptides, CART I (55-102) and CART II (62-102), each containing three potential disulphide bridges (Douglass et al., 1995; Thim et al., 1998; Dey et al., 2003; Dominguez, 2006).

CART peptides are evolutionarily strongly conserved between rodent and human (Douglass et al., 1995; Douglass and Daoud, 1996; Adams et al., 1999), with about 95\% amino-acid identity between the active neuropeptides (Douglass and Daoud, 1996; Thim et al., 1998; Yermolaieva et al., 2001; Dominguez, 2006), suggestive of a conserved critical physiological function. Notably, high levels of CART expression have been identified to localize in brain regions that include the arcuate nucleus (Arc), the lateral hypothalamus area (LHA), the paraventricular nucleus (PVN), and the nucleus accumbens (Acb) (Douglass et al., 1995; Gautvik et al., 1996; Couceyro et al., 1997; Koylu et al., 1997, 1998; Kristensen et al., 1998; Vrang et al., 1999a; Hubert and Kuhar, 2008; Cavalcante et al., 2011), suggesting an important role for CART in the regulation of food intake and energy homeostasis. This is consistent with results from injections of CART peptide into the nucleus accumbens which have shown an inhibition of feeding in rodents (Yang and Shieh, 2005; Jean et al., 2007). In addition, CART in the Arc is co-localized with $\alpha$-melanocyte stimulating hormone ( $\alpha$-MSH) (Chronwall, 1985; Adam et al., 2002), which is produced from the proopiomelanocortin (POMC) precursor and is a major inhibitor of appetite and food intake (Fan et al., 1997; Kim et al., 2000; Zheng et al., 2005). In the Arc, CART mRNA levels are regulated by circulating leptin (Kristensen et al., 1998; Schwartz et al., 2000) and are increased by peripheral leptin administration (Elias et al., 1998; Kristensen et al., 1998; Wang et al., 1999; Elias et al., 2001), again indicative of a critical role in energy balance regulation. Moreover, injection of CART I (55-102) into the PVN or Arc of rats markedly enhanced the mRNA expression for the uncoupling protein-1 (UCP-1) in brown adipose tissue, relating CART peptides not only to the control of feeding but also the modulation of energy expenditure (Wang et al., 2000; Kong et al., 2003). Mechanistically, it has been shown that application of CART I (55-102) to hypothalamic explants can stimulate the release of corticotropin-releasing hormone (CRH) and thyrotropin releasing hormone, which further links CART to the regulation of the hypothalamic-pituitary-adrenal axis (Stanley et al., 2001). Importantly, several genetic studies have associated mutations or polymorphisms in the CART gene in humans with obesity, clearly demonstrating a crucial role of CART in the control of energy homeostasis also in humans (Hager et al., 1998; Challis et al., 2000; del Giudice et al., 2001; Yamada et al., 2002; Dominguez 
et al., 2004a; Guerardel et al., 2005; Yanik et al., 2006; Rigoli et al., 2010).

While a specific CART receptor(s) has not been identified to date, there is strong evidence that CART signaling can be blocked by pertussis toxin (PTX), indicative of the involvement of an inhibitory G-protein-coupling receptor that couples to $\mathrm{G}_{\mathrm{i} / \mathrm{o}}$ proteins (Yermolaieva et al., 2001; Lakatos et al., 2005; Sen et al., 2007). For example, CART I (55-102) has been described to inhibit voltage-gated L-type $\mathrm{Ca}^{2+}$ channels in hippocampal neurons, an effect that was blocked by treatment with PTX (Yermolaieva et al., 2001). Furthermore, central administration of CART I (55-102) stimulated the phosphorylation of cyclic AMPresponse-element-binding protein (CREB) in $\mathrm{CRH}$ neurons in the PVN of fasted and fed rats (Sarkar et al., 2004), which again is classified as a PTX-sensitive mechanism. Finally, CART I (55102) application activated extracellular signal-regulated kinase (ERK) phosphorylation in the rodent pituitary-derived cell lines, AtT20 and GH3, and such CART-induced effects were attenuated by a MEK kinase inhibitor as well as pre-treatment with PTX (Lakatos et al., 2005), further supporting the mediation of CART action by inhibitory $\mathrm{G}$ proteins.

\section{DISTRIBUTION OF CART EXPRESSION}

CART can be found in both the central nervous system (CNS) (Spiess et al., 1981; Douglass et al., 1995; Gautvik et al., 1996; Couceyro et al., 1997; Koylu et al., 1997; Smith et al., 1999; Hubert and Kuhar, 2005, 2008; Dominguez, 2006; Vrang, 2006) and the periphery (Koylu et al., 1997; Broberger et al., 1999; Ekblad et al., 2003; Larsen et al., 2003; Wierup et al., 2004; Ekblad, 2006; Vicentic, 2006; de Lartigue et al., 2007; Kasacka et al., 2012). $C A R T$ mRNA-containing neurons are present in high densities in diverse regions such as the Edinger-Westphal nucleus, ganglion cells in the retina, mitral and tufted cells of the olfactory bulb, sensory barrels in the cerebral cortex, the pituitary, lamina $\mathrm{X}$ of the spinal cord, medulla of the adrenal cortex, the vagal nuclei, and a number of hypothalamic nuclei (Douglass et al., 1995; Couceyro et al., 1997). Expression of CART in peripheral blood and pituitary portal has also led to the identification of CART-positive neuroendocrine neurons in the hypothalamus, where CART was demonstrated to constitute a releasing factor delivered to the hypothalamic-pituitary-adrenal (HPA) portal circuit for potential endocrine regulation (Larsen et al., 2003; Vicentic, 2006). Consistent with a role in energy homeostasis, CART expression has also been associated with glucose-sensing sites both centrally and peripherally, in both rodents and humans (Jensen et al., 1999; Wierup et al., 2005, 2006, 2007; Kasacka et al., 2012). In the periphery, CART expression has been identified in the islet endocrine cells, ganglionic cells, as well as the sensory and autonomic nerve fibers of the pancreas (Jensen et al., 1999; Wierup et al., 2006, 2007; Kasacka et al., 2012). A recent paper also reported the expression of CART mRNA and protein in subcutaneous and visceral white adipose tissues from both rat and human (Banke et al., 2013), serving a potential novel role in adipocytes by fine-tuning lipolysis and lipase activation to affect lipid- and glucose-homeostasis (Vasseur et al., 2007; Banke et al., 2013).

In addition to the structural conservancy between CART isoforms across species (Douglass et al., 1995; Douglass and
Daoud, 1996; Adams et al., 1999; Dey et al., 2003), functional conservation of CART in the mammalian neuroendocrine system has also been implicated in the resembling CART mRNA and peptide distribution pattern in the brain observed between humans, rodents, as well as monkeys (Douglass and Daoud, 1996; Gautvik et al., 1996; Charnay et al., 1999; Cavalcante et al., 2011). As a leptin-regulated neurotransmitter with potent appetite-suppressing activity (Kristensen et al., 1998), CART expression in the CNS is highly localized to distinct brain areas critically involved in the control of energy homeostasis, limbic and sensory functions, as well as throughout the HPA axis (Douglass et al., 1995; Gautvik et al., 1996; Koylu et al., 1997; Charnay et al., 1999; Dominguez, 2006; Hubert and Kuhar, 2008; Cavalcante et al., 2011). Localization analyses of CART expression at the mRNA and peptide levels have demonstrated concordance across studies applying cDNA sequencing (Douglass et al., 1995), in situ hybridization (Douglass et al., 1995; Couceyro et al., 1997) and immunohistochemistry (Koylu et al., 1997). Indeed, CART mRNA has been shown to constitute the third most abundant transcript identified in rat hypothalamus after subtraction of cerebellar and hippocampal mRNAs (Gautvik et al., 1996).

\section{CENTRAL CART IN THE REGULATION OF APPETITE AND ENERGY HOMEOSTASIS}

A considerable amount of information has been accumulated for the role of CART in modulating metabolism via actions within the CNS. Together with several other critical neuropeptides, CART is integrated into the circuits that control the overall regulation of energy balance. The major site of action is the hypothalamic arcuate nucleus located at the base of the hypothalamus in an area where the blood-brain barrier is semi-permeable, hence uniquely assessable to circulating humoral and metabolic mediators (Barsh and Schwartz, 2002; Berthoud, 2002; Faouzi et al., 2007). As a consequence, the arcuate nucleus circuit serves as sensor of whole-body energy status represented by adiposity levels and promptly directs downstream responses accordingly through neuronal signaling to maintain a constant level of fuel stores (Schwartz et al., 2000; Barsh and Schwartz, 2002).

Two sets of neurons with reciprocal metabolic effects reside in the Arc, namely the orexigenic neuropeptide Y (NPY)/AgRP neurons which promote food intake and reduce energy expenditure, and the adjacent anorexigenic POMC/CART neurons that inhibit food intake and increase energy expenditure (Chronwall, 1985; Elmquist et al., 1998; Barsh and Schwartz, 2002). In response to circulating hormones, such as leptin and insulin that are secreted from adipose tissues and the pancreas, respectively, with a plasma level proportionate to body adipose stores (Zhang et al., 1994; McGregor et al., 1996; Ostlund et al., 1996), hypothalamic expression of the two sets of neurons is differentially regulated (Schwartz et al., 2000). For instance, leptin and insulin levels are reduced following food deprivation that lowers body fat stores, which inhibits POMC/CART neurons and stimulates NPY/AgRP neurons (Schwartz et al., 2000). In addition, the NPY/AgRP neurons are also subject to activation by the circulating orexigenic peptide ghrelin released from the stomach with peak levels before meal initiation (Nakazato et al., 2001). 
NPY/AGRP and POMC/CART neurons are not merely two independent sensors mediating opposing effects and projecting parallel extensions to second-order hypothalamic neuropeptide neurons, activity of the two pairs of neurons is subject to regulation by a multitude of mechanisms involved in the control of energy homeostasis. For instance, neuroanatomical studies have shown that there are intra-arcuate connections between the two neuronal subgroups, which are autoregulated by melanocortin peptides as well as local $\gamma$-aminobutyric acid (GABA)-mediated effects (Bagnol et al., 1999; Cowley et al., 2001). POMC/CART neurons express the melanocortin 3-receptor (MC3-R) which is specific for melanocortin peptides derived from the posttranslational cleavage of POMC (Bagnol et al., 1999), such as the anorectic $\alpha$-MSH (Fan et al., 1997; Huszar, 1997; Kim et al., 2000; Zheng et al., 2005). The activation of a subset of Arc POMC/CART neurons following exposure to leptin via leptin receptors has been reported to impose an autoinhibitory effect exerted through MC3-R activation in response to elevated release of POMC-derived peptides (Elias et al., 1998; Ahima et al., 1999; Cowley et al., 2001). However, inconsistency exists with the proposed negative autoreceptor manner of MC3-R in diminishing POMC/CART neuronal activity due to the mild increase in adiposity and body weight observed in MC3-R-deficient mice (Butler et al., 2000; Chen et al., 2000). In addition to the potential feedback mechanism described above, the inhibitory neurotransmitter GABA constitutes a principal modulator in the complex intra-arcuate circuit (Cowley et al., 2001). Subpopulations of Arc neurons harbor colocalized expression of NPY and GABA (Horvath et al., 1997), where GABA released from the orexigenic NPY/GABA terminals induces inhibitory post-synaptic currents (IPSCs) that consequently hyperpolarizing hence decreasing firing rate of the post-synaptic POMC/CART neurons (Cowley et al., 2001). Besides such direct neuronal innervations synapsing into Arc POMC/CART neurons by GABA-secreting NPY neurons (Cowley et al., 2001), a recent investigation has demonstrated the direct action of leptin on hyperpolarizing presynaptic GABAergic neurons in reducing GABA-mediated inhibitory tone to POMC/CART cells (Vong et al., 2011), whilst ghrelin was shown to trigger the opposite events on the same neurons (Cowley et al., 2003). Collectively, the electrophysiological regulation of arcuate POMC/CART neurons constitutes two primary mechanisms, including the direct effects of potent neuropeptide modulators on membrane potential through influencing ion channel activity, as well as the indirect impacts on IPSC frequency marking GABA inhibition from local NPY/GABA neurons (Cowley et al., 2001). The resultant resting action potential is purported to concurrently involve the autoregulatory effects of melanocortin peptides (Cowley et al., 2001), ultimately providing an integrated circuit at the Arc for the regulation of food intake and energy homeostasis.

Present in both classic neuroendocrine neurons and hypothalamic projection neurons, Arc CART displays an almost 100\% colocalization with POMC and complete segregation from the more medially located orexigenic NPY in rodents (Elias et al., 1998; Vrang et al., 1999a; Fekete et al., 2000, 2004). The coexistence of CART with POMC and derivatives such as $\alpha-\mathrm{MSH}$ were found to persist throughout the rostrocaudal extent of the Arc (Vrang et al., 1999a), wherein CART immunoreactivity (IR) was depicted in a separate study to pervade all $\alpha$-MSHIR perikarya and axons (Menyhért et al., 2007), which accords with the anorectic role widely adopted for POMC/CART neurons. In accordance with established neuronal projections from Arc (Schwartz et al., 2000), all $\alpha$-MSH-IR axons in the PVN have also been shown to contain CART immunoreactivity (Menyhért et al., 2007).

In addition to co-storage with the POMC and associated cleavage products which promote negative energy balance (Fan et al., 1997; Huszar, 1997; Kim et al., 2000; Zheng et al., 2005), CART exhibits $>95 \%$ colocalization with the orexigenic melaninconcentrating hormone (MCH) (Qu et al., 1996; Rossi et al., 1997; Ludwig et al., 1998) at the LHA and zona incerta (ZI) (Vrang et al., 1999a; Elias et al., 2001; Menyhért et al., 2007). All MCHpositive cells showed immunoreactivity for CART in the rostral ZI and the most medial region of LHA, whilst an increasing number of non-CART MCH cells were detected in the caudal and lateral parts of the LHA apart from the CART-containing $\mathrm{MCH}$ neurons (Vrang et al., 1999a). In regard to the extensive hypothalamic colocalization of CART-IR with both anorexigenic and orexigenic neurotransmitters, namely POMC at the Arc and $\mathrm{MCH}$ at the LHA and ZI respectively, it has been hypothesized that CART co-stored within POMC-IR neurons, functions to counteract the effects of $\mathrm{MCH}$ in feeding stimulation, on the assumption that CART and MCH may be co-released (Shimada et al., 1998; Vrang et al., 1999a). This is supported by the observation of an elevated CART tone in the MCH-IR LHA neurons in $\mathrm{MCH}$ knockout mice, which exhibited anorexic tendencies marked by hypophagia and a leaner phenotype (Shimada et al., 1998; Vrang et al., 1999a). Interestingly, no colocalization was found between CART and another orexigenic peptide confined to neurons in the LHA, orexin B (de Lecea et al., 1998; Peyron et al., 1998; Sakurai et al., 1998; Vrang et al., 1999a), which increases in transcription activity during fasting to elicit stimulatory effects on feeding (Sakurai et al., 1998).

Colocalization experiments exploring the resemblance of CART distribution in feeding-related neuronal groups of the human hypothalamus revealed that, while overlap is seen in certain areas, some striking differences in colocalization pattern also exist (Charnay et al., 1999; Elias et al., 2001; Menyhért et al., 2007). For example, the close overlap of CART and POMC expression in rodents is not so obvious in the human brain (Mihaly et al., 2000; Menyhért et al., 2007). In particular, CART expression could not be detected in the perikarya and axons of $\alpha-\mathrm{MSH}-\mathrm{IR}$ neurons but interestingly was found in approximately $30 \%$ of NPY/agouti-related protein (AgRP) neurons (Mihaly et al., 2000) in the human infundibular nucleus analogous to the Arc in rodents (Menyhért et al., 2007). However, similar co-expression patterns of CART and other neurotransmitters between human and rodents were seen in the PVN region (Menyhért et al., 2007). Intriguingly, the co-expression of CART in NPY/AgRP instead of POMC neurons of the Arc was also observed in other primates such as monkeys (Grayson et al., 2006). Comparable with the observation in rodents, CART was demonstrated to colocalize with $\mathrm{MCH}$ in the lateral hypothalamus of humans, particularly in the perifornical region where up 
to $50 \%$ overlap in immunoreactivities of the two peptides was detected (Menyhért et al., 2007). In the infundibular nucleus, fibers comprising $\mathrm{MCH}-\mathrm{IR}$ were also observed in a portion of CART-IR axons, suggestive of lateral hypothalamic origin (Menyhért et al., 2007).

It is of particular interest that CART in humans has been shown to exhibit the contrasting colocalization with the orexigenic NPY/AgRP neurons and complete segregation from POMC-containing cells in the infundibular nucleus analogous to the rodent arcuate nucleus, whilst co-storage with $\mathrm{MCH}$ remained in the lateral hypothalamus. Speculations entailing an orexigenic role of CART as well as the involvement in other functions have therefore arisen, which is supported by the elevated food intake following CART administration to the PVN even in rodents (Stanley et al., 2001). Such paradoxical potentials of CART in feeding behaviors as evident in multiple pharmacological and physiological studies will be discussed subsequently in the present review. With regard to the resembling colocalization with the orexigenic $\mathrm{MCH}$ in the LHA consistent across species investigated (Ludwig et al., 1998; Vrang et al., 1999a; Elias et al., 2001; Menyhért et al., 2007), although CART expression appeared unaffected by alterations in energy homeostasis in the $\mathrm{MCH}$ neurons in rodents, $\mathrm{MCH}$ administration effectively blocked intracerebroventricular CART-induced stimulation of central dopaminergic neurons (Yang and Shieh, 2005). Indeed, lateral hypothalamic CART synthesis has been linked to the regulation of dopaminergic reward pathways (Philpot and Smith, 2006), where psychostimulant-like effects were modulated by CART through moderating the activities of dopaminergic neurons (Jaworski et al., 2003; Dominguez et al., 2004b; Kuhar et al., 2005). Thus, while possibility exists that CART and $\mathrm{MCH}$ may participate in regulating different physiological functions effectuated by the same neuronal groups, anatomical and functional interplay of the two peptides has been indicated to prevail in the interactions between food intake and reward neurocircuitries (Saper et al., 2002; Yang and Shieh, 2005; Pang and Han, 2012). Knowledge regarding the underlying cellular mechanisms awaits further extension through neuronal mapping and biochemical studies.

While the role of CART in controlling appetite and energy homeostasis in the human system might be somewhat different, in rodents, the neuronal network in which CART is involved to modulate energy homeostasis has been well-described. The expression of endogenous CART at brain regions involved in feeding regulation has been shown to be sensitive to the energy balance status and the genetic background of mice. In brief, fasting has been documented in various mammals to reduce CART mRNA levels at the hypothalamic PVN, Arc, perifornical region, as well as the nucleus accumbens shell (AcbSh) of the striatum, whilst refeeding restored the expression (Kristensen et al., 1998; Lambert et al., 1998; Adams et al., 1999; Vrang et al., 1999a, 2000; Henry et al., 2001; Li et al., 2002; Yang and Shieh, 2005; Van Vugt et al., 2006; Germano et al., 2007). As a leptinregulated neurotransmitter, the expression of CART mRNA and peptide levels at the Arc is described to be positively correlated with circulating leptin levels (Kristensen et al., 1998; Ahima et al., 1999; Ahima and Hileman, 2000; Rohner-Jeanrenaud et al., 2002; Wortley et al., 2004). This relationship between leptin and
CART levels was less consistently demonstrated at the PVN and LHA (Wortley et al., 2004), despite evidence supporting a pivotal role of CART-containing neurons projecting from the Arc to the second order neurons located in the PVN and LHA in producing anorexia (Elias et al., 1999; Wang et al., 2000; Fekete et al., 2004). Intravenous leptin administration was shown to induce Fos expression in hypothalamic CART neurons in the PVN, DMH, Arc, and the ventral premammillary nucleus (Elias et al., 1998, 2001). Whilst Arc CART mRNA and peptide levels were strongly downregulated in food-deprived animals, the transcripts were nearly absent in genetically obese $f a / f a$ rats and $o b / o b$ mice with disrupted leptin signaling, wherein daily intraperitoneal leptin treatment led to CART restoration in the Arc and DMH (Friedman and Halaas, 1998; Kristensen et al., 1998; Ahima et al., 1999; Ahima and Hileman, 2000; Rohner-Jeanrenaud et al., 2002), suggesting that leptin-induced anorexigenic actions may be mediated via CART neurons at the Arc. In comparison, in the anx/anx anorexia mouse model characterized by marked reduction in feeding and premature death, CART expression was significantly lower in the Arc, and less prominently in the DMH and LHA regions (Johansen et al., 2000). The reduced Arc CART expression, together with downregulated serum leptin levels, was attributed to a compensatory response to the energy-deprived state, as well as a probable molecular defect in the Arc deregulating the cellular source of CART mRNA (Johansen et al., 2000). In contrast with genetically obese animal models, diet-induced obese (DIO) rodents subjected to a high fat diet (HFD) have been shown to display higher Arc CART mRNA levels compared with lean animals fed a low fat diet, due to hyperleptinaemia (RohnerJeanrenaud et al., 2002; Wortley et al., 2004; Hou et al., 2010). Elevated CART transcript levels were also found in normalweight obesity-prone rats compared to obesity-resistant subjects, where the Arc leptin-CART pathway was proposed to respond to fat-rich dietary intervention through inhibiting excessive body fat accrual by substituting lipid storage with lipid mobilization (Rohner-Jeanrenaud et al., 2002; Wortley et al., 2004).

Despite purported relevance of CART in the modulation of gastrointestinal (GI) function, it is at present unclear the definite roles of enteric CART in intestinal motility, satiety and feeding behavior (Okumura et al., 2000; Ekblad et al., 2003; Smedh and Moran, 2003; Tebbe et al., 2004). Convincing evidence supporting the GI effects of CART have been provided by independent investigations, where central injections of CART in rodents elicited an anorexigenic response accompanied by the inhibition of gastric emptying and gastric acid secretion (Okumura et al., 2000; Asakawa et al., 2001; Smedh and Moran, 2003), while colonic motility measured by colonic transit time was accelerated (Tebbe et al., 2004). Contrary to a local ENS effect, such alterations in GI functions were indicated to be conveyed through CART acting in the CNS (Okumura et al., 2000; Ekblad et al., 2003; Smedh and Moran, 2003, 2006; Tebbe et al., 2004), as intraperitoneal (i.p.) CART administration failed to reduce food consumption or reproduce similar gastric responses (Okumura et al., 2000; Tebbe et al., 2004; Skibicka et al., 2009). Furthermore, pretreatment with central injection of CRH receptor antagonist prior to central CART administration completely abolished the CARTinduced gastric effects, suggesting a central CART-directed CNS 
modulation of the digestive tract behavioral motor functions via CRH-dependent mechanisms (Okumura et al., 2000; Smedh and Moran, 2003, 2006; Tebbe et al., 2004).

Consistent with a potential CART pathway connecting gut-brain signals in the control of food intake, co-expression of CART and the satiety factor cholescystokinin (CCK)-1 receptors has been detected in the $f$ afferent neurons in rodents (Crawley et al., 1991; Moran et al., 1992; Mercer and Beart, 1997; Koylu et al., 1998; Broberger et al., 1999; Dun et al., 2001; Lodge and Lawrence, 2001; Zheng et al., 2002; de Lartigue et al., 2007). Substantially, the synergistic effect of CART and the anorexigenic gut hormone CCK (Crawley and Corwin, 1994) on food intake regulation analogous to that documented for leptin and CCK (Barrachina et al., 1997; Broberger et al., 1999; Morton et al., 2005; Merino et al., 2008) has been demonstrated in animal studies, during which the responses to simultaneous as well as separate central administration of CART peptide and the CCK octapeptide (CCK-8) through cannula implantation (Maletinska et al., 2007) were compared (Volkoff, 2006; Maletinska et al., 2008). In fasted lean mice, the anorexigenic effect induced by CART delivery was significantly enhanced by parallel CCK- 8 injection when compared with the administration of each particular peptide alone, while the additive reaction was also shown in an open field test where locomotor activity of the subjects was inhibited (Maletinska et al., 2008). On the contrary, application of the CCK-1 receptor antagonist devazepide blocked CART-induced alteration in food intake (Maletinska et al., 2008). Such long-lasting cooperative action on feeding was speculated to associate in turn with the synergistic effect of leptin on CCK-induced satiety, where CART release from the nodose ganglia was mediated by the interaction of low-affinity vagal CCK-1 receptors and leptin receptors to produce short-term satiety (Maletinska et al., 2008; Heldsinger et al., 2012). Furthermore, 17 and $41 \%$ of vagal afferent neurons projecting from the nodose ganglia to the stomach and duodenum respectively were identified to be CART-immunoreactive (Zheng et al., 2002). The vagus has been proposed a mediator of the dorsal hindbrain action of CART on gastric motor function, as indicated by the inhibitory gastric effects of hindbrain intracerebroventricular (i.c.v.) CART microinfusion, which was blocked by subdiaphragmatic vagotomy (Smedh and Moran, 2003, 2006). In particular, the dorsal vagal complex (DVC) was demonstrated to be a target site for both CART and CRH in the suppression of gastric emptying, where effective inhibition occurred in response to the intraparenchymal injection of either peptide into the DVC, at a lower dose compared to that required to elicit a noticeable inhibitory effect by hindbrain i.c.v. administration (Smedh and Moran, 2006).

Reciprocal of a central CART-directed modulation of gastric behavior in feeding regulation, the anorectic actions of central CART have also been proposed to result from stimulation by gut hormones (Hunter et al., 2004). Following food intake, CCK released in the GI tract has been delineated to direct CART release from central vagal afferents, where an abundance of $C C K-1$ receptor mRNA expression was detected in the nodose ganglion (Broberger et al., 1999; Hunter et al.,
2004). CCK-borne information is then mediated by CART to the hindbrain sites where suppression of food intake is elicited (Broberger et al., 1999; Hunter et al., 2004). However, the role of CART released from vagal afferent terminals in the commissural part of the nucleus of the solitary tract (NTS) was suggested to be minor in mediating vagal satiety signals, as a diminished suppression of food intake was exerted by direct NTS subnuclei CART injections compared to hindbrain i.c.v. CART (Zheng et al., 2001, 2002; Skibicka et al., 2009). Thus, the potential function of CART on satiation may involve a distal site of action as well as interaction with other nutritional transmitters critical for vagally-mediated gastrointestinal satiety (Broberger et al., 1999; Zheng et al., 2002). For instance, induction of CART immunoreactivity was readily demonstrated upon CCK administration both in rats and cultured vagal afferent neurons in a state of energy restriction, while refeeding of starved animals markedly increased CART immunoreactivity via a CCK-1 receptor antagonist-sensitive mechanism (de Lartigue et al., 2007, 2010). In addition, introduction of the orexigenic peptide ghrelin inhibited CCK-mediated CART stimulation (de Lartigue et al., 2007), illustrating an interplay between gastrointestinal orexigenic and anorexic peptides in modulating CART expression. In particular, immunoreactive CART neurons have been shown to display differential quantities during developmental changes in the dorsal motor nucleus of the vagus (DMNV), wherein vagal preganglionic neurons are responsible for regulating various ingestive behaviors through innervations in the GI tract (Dun et al., 2001; Zheng et al., 2002). Such descending expression levels upon maturation indicate a potential signaling role of CART critical in the early post-natal development (Dun et al., 2001).

\section{PERIPHERAL CART IN THE REGULATION OF ENERGY HOMEOSTASIS}

The proposed physiological role of CART as an endogenous anorexigenic factor was originally deduced from the inhibition of food consumption observed in animal models following hypothalamic or intracerebroventricular administration of CART-derived peptides (Kristensen et al., 1998; Vrang et al., 1999b; Larsen et al., 2000; Volkoff and Peter, 2000; Aja et al., 2001a,b; Stanley et al., 2001; Nakhate et al., 2011, 2013). Based on the dual involvement in both hypothalamic modulation of feeding behavior and autonomic control of gastrointestinal functions common to many neuropeptides, considerable efforts have subsequently been devoted to the investigation of CART-mediated effects in the enteric nervous system (ENS) (Couceyro et al., 1998; Kuhar and Yoho, 1999; Murphy et al., 2000; Okumura et al., 2000; Ekblad et al., 2003; Ellis and Mawe, 2003; Smedh and Moran, 2003; Tebbe et al., 2004). Extensive CART expression has been characterized in the ENS of diverse mammals by in situ hybridization (Ekblad et al., 2003) and immunoassays (Couceyro et al., 1998; Kuhar and Yoho, 1999; Murphy et al., 2000; Ellis and Mawe, 2003; Kasacka et al., 2012), affirming the presence of CART mRNA and peptides in nerve cell bodies and fibers innervating the stomach, small and large intestines of the gastrointestinal tract (Ekblad, 2006), particularly within the neuroendocrine cells and myenteric plexus (Kasacka et al., 2012). Such brain-gut CART 
expression suggests that CNS control of feeding and satiety may be coordinated with local gastric CART-induced effects to produce an integrated regulation of body weight. This is supported by the central CART immunoreactivity profile, which depicts concentrated expression at the hypothalamic nuclei (Spiess et al., 1981; Douglass et al., 1995; Gautvik et al., 1996; Couceyro et al., 1997; Koylu et al., 1997; Smith et al., 1999; Hubert and Kuhar, 2005, 2008; Dominguez, 2006; Vrang, 2006) constituting major relays linking the sensory, motor and limbic areas between forebrain and hindbrain through widespread reciprocal networks, orchestrating autonomic, endocrine and behavioral activities (Fekete et al., 2000; Balkan et al., 2001; Williams et al., 2001; Tebbe et al., 2004). Specifically, anatomical implications of CART indicated by enteric CART expression in digestive function have been further indicated by CART immunoreactivity at the hypothalamic Arc and PVN neurons, as well as brainstem nuclei such as NTS and parabrachial nucleus (PBN), both involved in the efferent and afferent control of GI function through neuropeptidergic mechanisms engaging the complex neuroendocrine and autonomic pathways (Kristensen et al., 1998; Fekete et al., 2000; Aja et al., 2001b; Stanley et al., 2001; Zheng et al., 2001; Tebbe et al., 2003, 2004). In addition, CART expression in the cholinergic neurons of the myenteric plexus and the pancreatic islets further denoted the potential gastric effects of CART conducted via peripheral receptor targets composing the peripheral cholinergic pathways (Couceyro et al., 1998; Jensen et al., 1999; Ekblad et al., 2003; Tebbe et al., 2004; Wierup et al., 2004).

The precise functions of CART peptides released by enteric CART-expressing neurons in the ENS are yet to be determined (Ekblad, 2006). There has been a lack of direct evidence regarding a role of locally produced CART in classical neurotransmission within the GI tract, where intestinal motility as measured by contractile or relaxatory responses was unaffected by CART peptide application when motor activity studies were performed in vitro on muscle strips from stomach, small and large intestine (Ekblad et al., 2003). Notably, exceptions to the above may include specific CART-evoked colonic responses, such as the attenuation of nitric oxide-induced intestinal relaxation (Ekblad et al., 2003; Ekblad, 2006), as well as the apparent stimulation of colonic transit, an indirect measure of colonic motor function (Tebbe et al., 2004). In spite of the confined documentation of CART involvement in brain-gut interaction and the indeterminate functional role of enteric CART, accumulating evidence propose a role of CART in intestinal adaptation, where the survival and maintenance of enteric neurons is promoted (Ekblad et al., 2003; Ekblad, 2006). Such neuroprotective property (Ekblad, 2006; Zhang et al., 2012) and intestinal plasticity has been inferred from upregulated CART expression and increased CART-expressing neurons in atrophic intestine and cultured myenteric neurons respectively, conditions indicative of neuronal stress or injury (Ekblad et al., 2003; Ekblad, 2006). In sum, gastric involvement of CART has been evident through discrete histological and physiological experiments, whilst further detailed characterization of distribution and functions may contribute to a comprehensive understanding of the specific roles of enteric CART.

\section{FUNCTIONAL IMPLICATIONS OF CART ON ENERGY METABOLISM FROM PHARMACOLOGICAL INTERVENTIONS}

The identification of the underlying mechanisms by which CART exerts effects on feeding and energy homeostasis have been challenging due to the lack of any knowledge of the corresponding CART receptor (s) and the absence of specific antagonists. Nevertheless, numerous studies incorporating both pharmacological and genetic manipulations of CART expression in murine models have been endeavored in the last decades to determine the sites of action and the effects on feeding behavior and metabolism of the peptide. Overexpression studies to discern the brain regions mediating CART-induced regulation of feeding have been the most common approach in rodents. Widely adopted as an appetite-regulating peptide of the CNS with hypothalamic expression levels modulated by nutritional status (Kristensen et al., 1998; Thim et al., 1998, 1999; Schwartz et al., 2000), CART was administrated i.c.v. to address the effects of overexpression during varying energy states (Kristensen et al., 1998; Lambert et al., 1998; Thim et al., 1998; Vrang et al., 1999b; Edwards et al., 2000; Kask et al., 2000; Larsen et al., 2000; Aja et al., 2001a,b; Bannon et al., 2001; Nakhate et al., 2011, 2013) (Table 1). The lateral ventricle ( $\mathrm{LV})$ of the forebrain or the 3 rd ventricle $(3 \mathrm{~V})$ have been the major injection targets. I.c.v. injection of recombinant CART peptide has been consistently demonstrated to inhibit food intake and body weight gain in a dose-dependent manner in both food-restricted and free-feeding conditions as well as both under standard chow or a nutritionally complete liquid diet, in either normal or diet-induced obese animals (Kristensen et al., 1998; Lambert et al., 1998; Thim et al., 1998; Vrang et al., 1999b; Edwards et al., 2000; Kask et al., 2000; Larsen et al., 2000; Abbott et al., 2001; Aja et al., 2001a,b; Bannon et al., 2001; RohnerJeanrenaud et al., 2002; Tachibana et al., 2003; Wortley et al., 2004; Qing and Chen, 2007; Nakhate et al., 2011, 2013). Furthermore, the catabolic capacity of CART appeared sufficient to prevent and attenuate the orexigenic effects of NPY, as i.c.v. and intra-PVN CART potently suppressed feeding in satiated rats subjected to NPY-induced hyperphagia (Kristensen et al., 1998; Lambert et al., 1998; Vrang et al., 1999b; Wang et al., 2000; Rohner-Jeanrenaud et al., 2002). Similarly, the anorectic potency of CART has also been demonstrated in a recent study focusing on the interaction between CART and the GABA type A receptor (GABA-A) active neurosteroid allopregnanolone (ALLO) and the inhibitor neurosteroid dehydroepiandrosterone sulfate (DHEAs) (Nakhate et al., 2013). It was shown in rodents that pre-treatment of i.c.v. CART effectively attenuated subcutaneous ALLO-induced hyperphagia and weight gain, as well as potentiating DHEAS-induced hypophagic and weight reducing effects (Nakhate et al., 2013).

CART administration via the i.c.v. route was also able to eliminate the increase in feeding and deleterious weight gain caused by social isolation in rats (Nakhate et al., 2011), a consequence of the downregulation of the hypothalamic CART-containing system in various hypothalamic feeding-related areas caused by this condition (Nakhate et al., 2011). In the same study, whilst resocialization of the isolation-reared rats restored the food intake, body weight, and hypothalamic CART-immunoreactivity back to controls levels, immunoneutralization of endogenous CART by i.c.v. CART antibody attenuated the restoration, confirming 


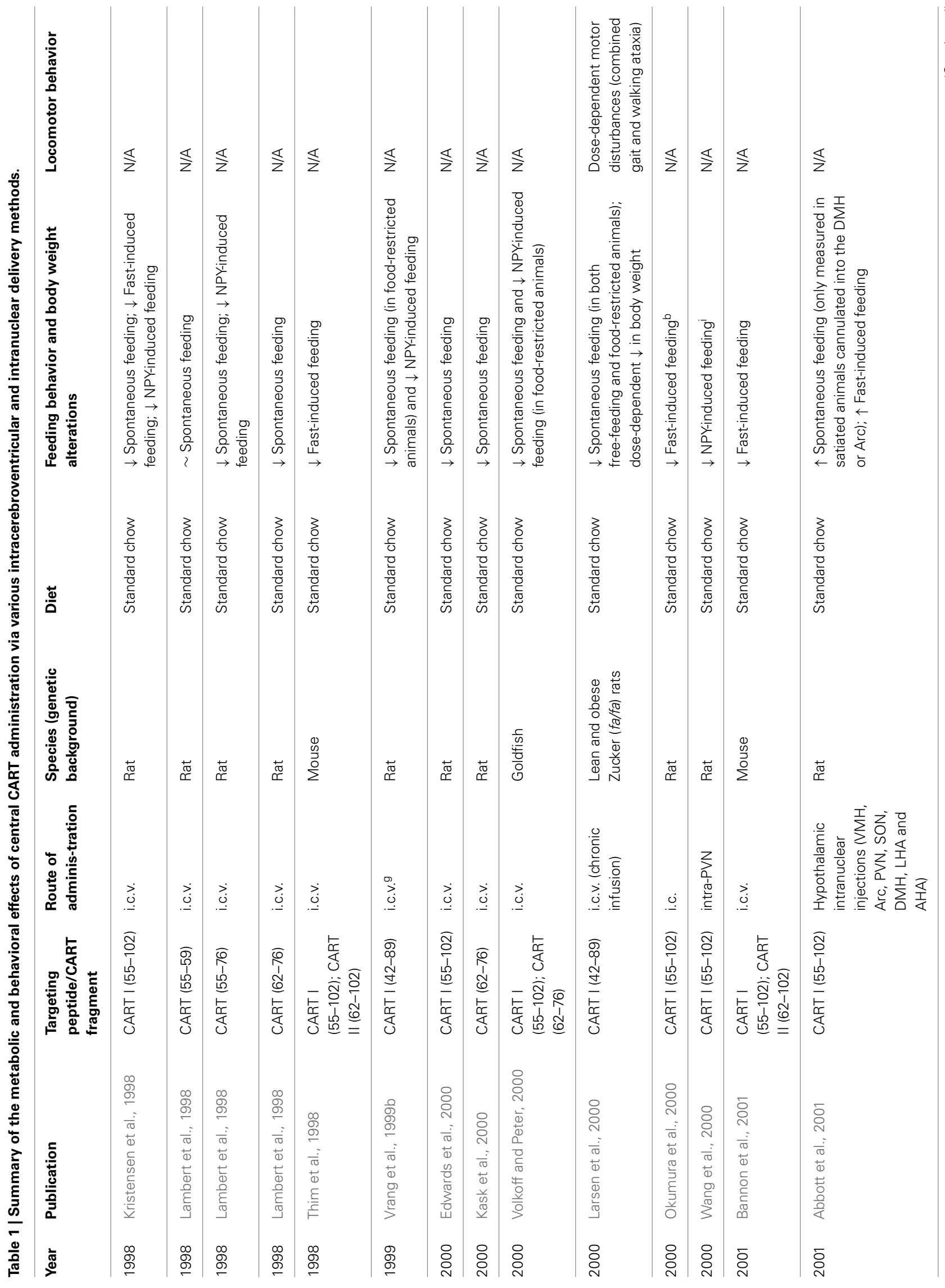




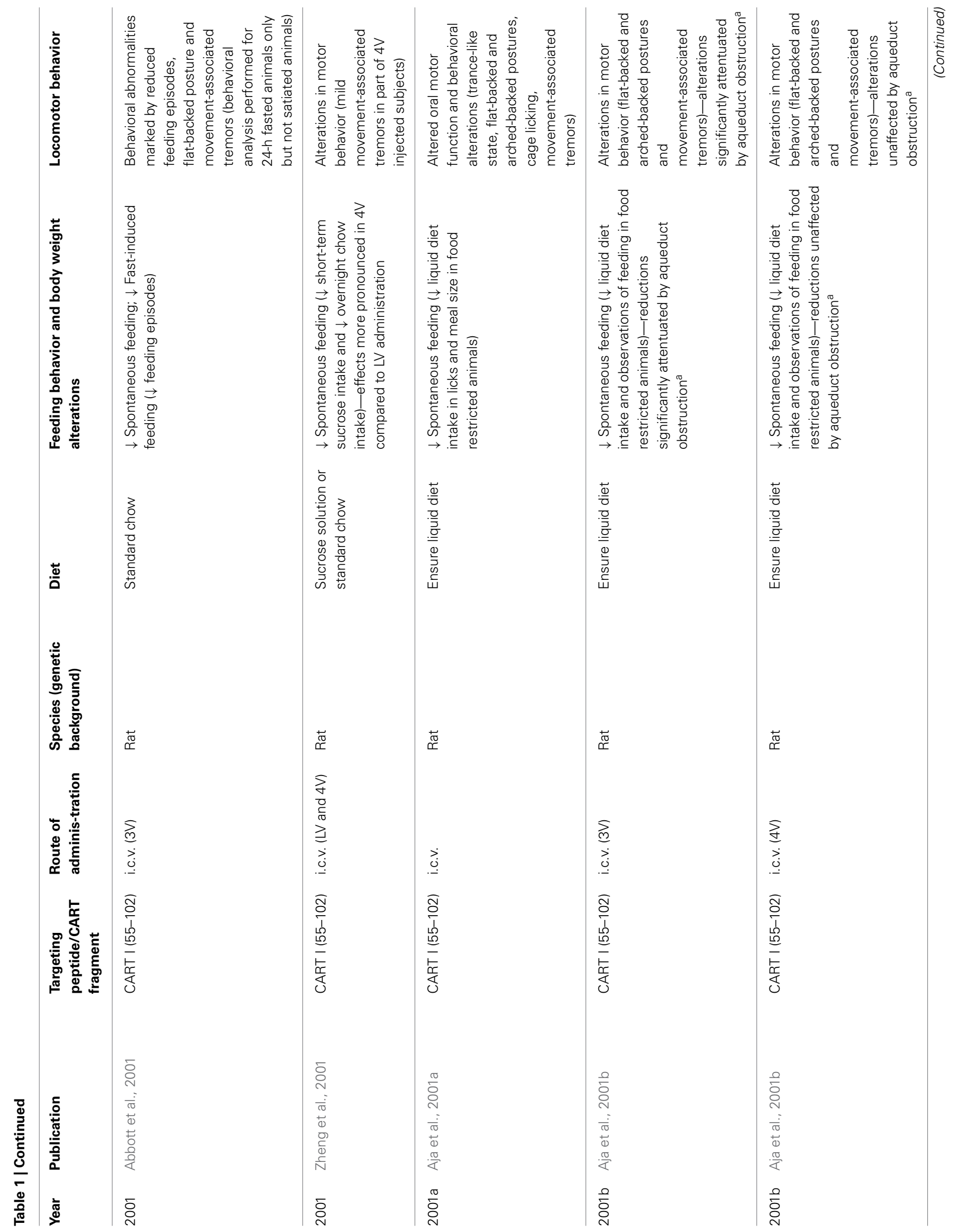




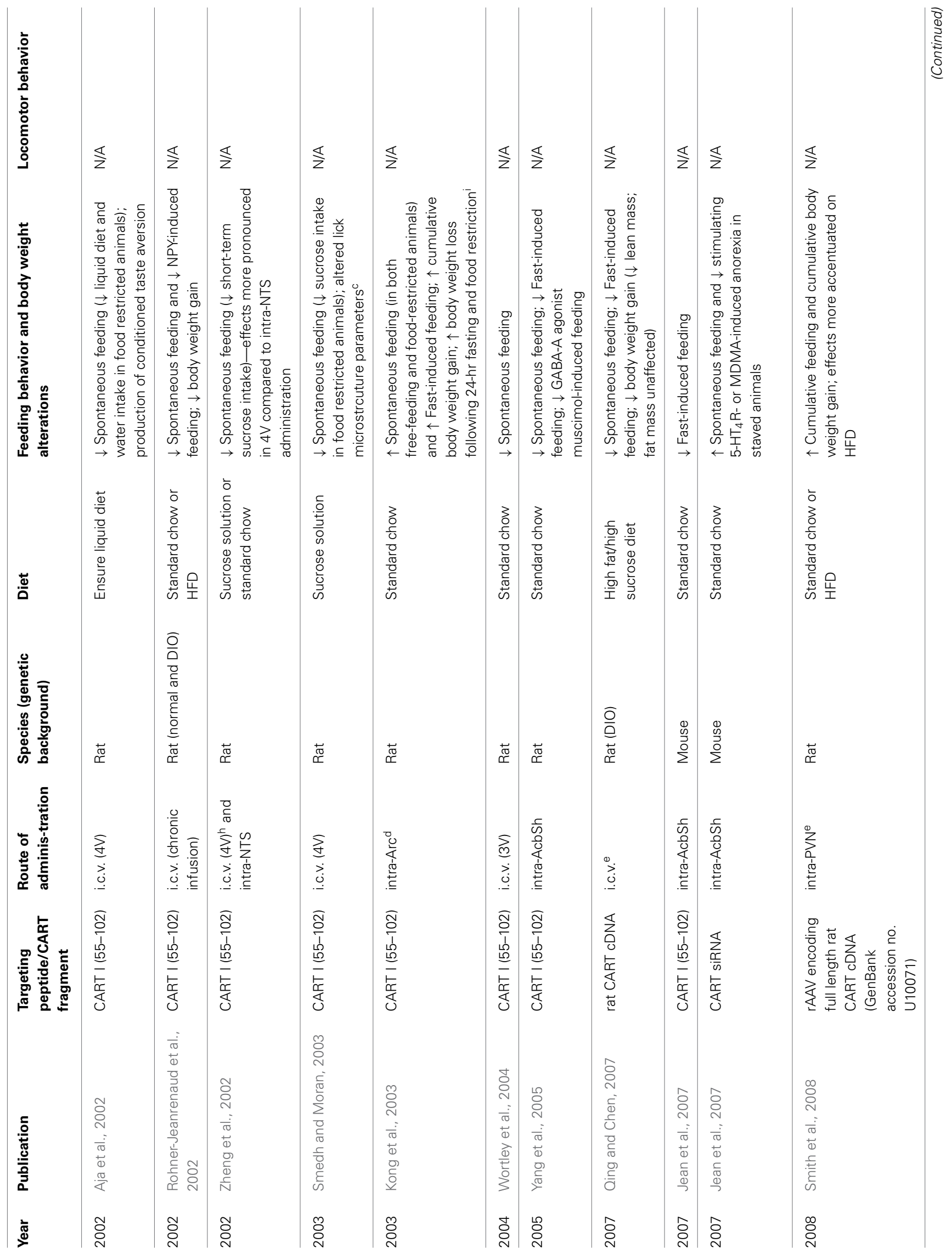




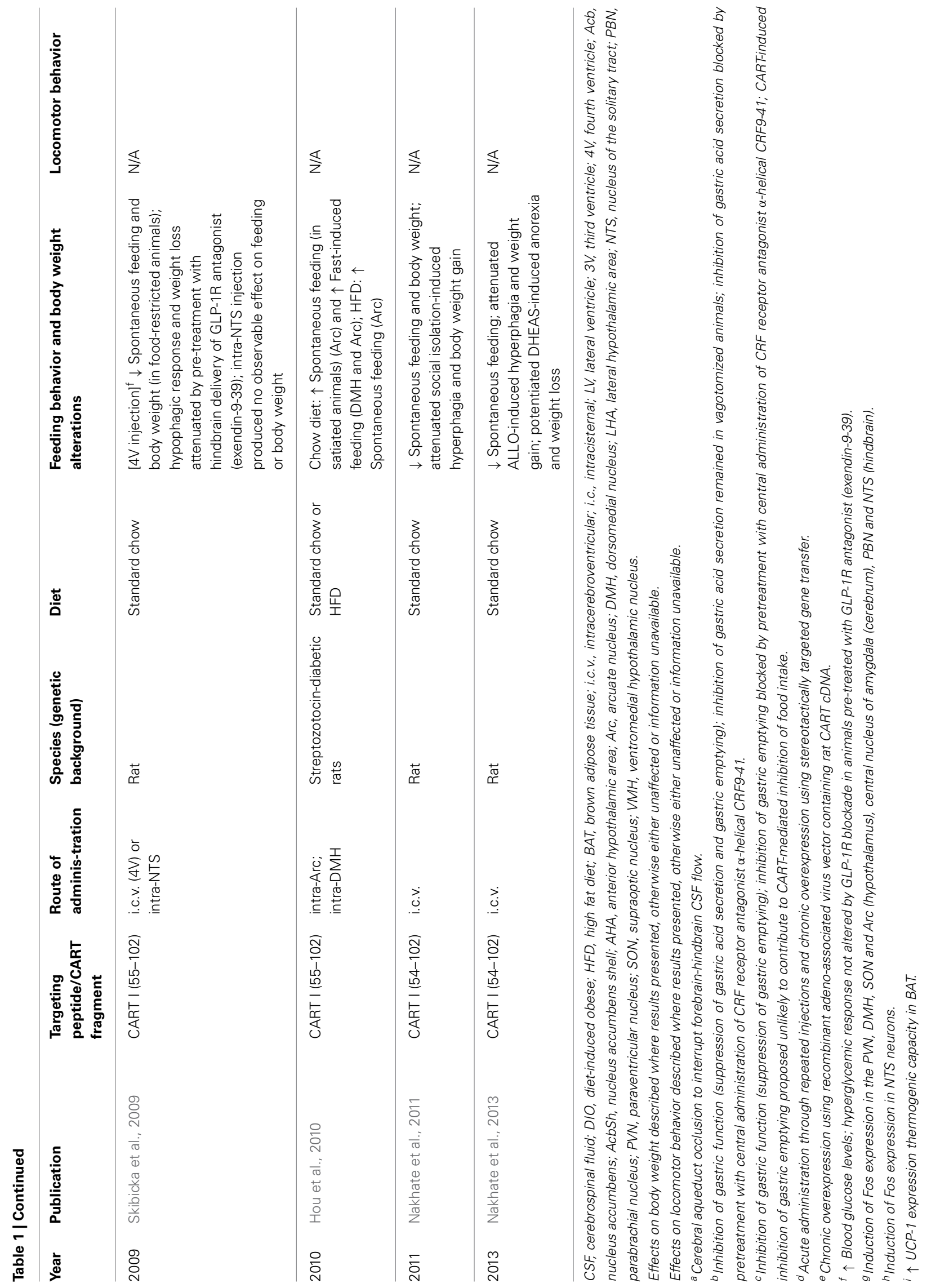


the important role of CART in feeding regulation under chronic psychological stress condition (Nakhate et al., 2011). This is consistent with other studies that used antibodies raised against different CART segments for blocking central CART signaling, where all of which were able to neutralize the anorectic property of CART and lead to a significant hyperphagic response (Kristensen et al., 1998; Lambert et al., 1998; Nakhate et al., 2010, 2011). In addition to eliciting an anorectic response, gastrointestinal effects including inhibition of gastric acid secretion and gastric emptying have also been reported as a result from i.c.v. CART (Okumura et al., 2000; Asakawa et al., 2001; Smedh and Moran, 2003, 2006; Tebbe et al., 2004). Chronic overproduction of CART mRNA via viral approaches or continuous infusion of recombinant CART peptide transferred through i.c.v. cannulas into genetically $(f a / f a)$ (Larsen et al., 2000) or diet-induced (Rohner-Jeanrenaud et al., 2002; Qing and Chen, 2007) obese rats induces hypophagic effects during fed states and reduced hyperphagia following fasting were also observed. Such reduction in energy intake was accompanied by suppression of body weight gain mainly due to decrease in lean mass (Larsen et al., 2000; Qing and Chen, 2007), indicating the potential of CART in the longterm regulation of food consumption and body mass, under both normal condition and nutritionally induced obesity.

In conjunction with the characterization of physiological responses, neuronal activities stimulated by central CART has been investigated by structural studies for the purpose of identifying brain areas potentially crucial for CART-induced anorectic effects. Following i.c.v. CART administration, temporal expression patterns of the immediate early gene $c$-Fos (Dragunow and Faull, 1989; VanElzakker et al., 2008), which has been adopted to depict neuronal firing of actions potentials (Dragunow and Faull, 1989; VanElzakker et al., 2008), were found to concentrate in the hypothalamic and brainstem structures implicated in the central regulation of feeding (Vrang et al., 1999b; Zheng et al., 2002). In the hypothalamus in particular, high density of Fos expression was located in the PVN and the posterior DMH, while considerable Fos-IR cells were also identified in the Arc and SO. In the brainstem, Fos-positive cell nuclei were also concentrated in the PBN and, more importantly, in the NTS, which serves a key sensory relay nucleus with reciprocal connections with numerous forebrain and brainstem structures (Vrang et al., 1999b). Such CART-induced Fos activation in the NTS has been indicated independent from possible secondary effects triggered by chemo-activation at the area postrema (AP) directed to the NTS, as the chemosensitive neurons in the AP were devoid of Fos-IR cells (Vrang et al., 1999b). Moderately high Fos expression was also detected in cerebral nuclei associated with autonomic functions and energy balance (Smith and DeVito, 1984; Vrang et al., 1999b), including the central nucleus of the amygdala, where neuronal projections also reciprocally link with the PVN of the hypothalamus and the PBN and NTS of the hindbrain (Hopkins and Holstege, 1978; Holstege et al., 1985). The widespread Fos expression pattern elicited by forebrain i.c.v. CART has been demonstrated to encompass an anatomical continuum of neuronal activations across the cerebrum, hypothalamus and brainstem (Vrang et al., 1999b). The paralleled effects on appetite inhibition and metabolic regulation are believed to portray an integrated outcome of the interactions between central CARTinterfered pathways residing primarily within the hypothalamic and brainstem neurons. For instance, as aforementioned, the administration of CART combined with other neuromodulatory such as CCK in mice generated synergistic effects on food intake and locomotion, while displaying concomitant enhancement in the number of Fos-positive neurons compared to injecting each peptide alone (Maletinska et al., 2008; Pirnik et al., 2010). The additive effect on Fos immunoreactivity was especially notable in the target areas common to both peptides, namely the hypothalamic PVN, DMH, VMH and Arc, as well as NTS at the brainstem (Maletinska et al., 2008; Pirnik et al., 2010), wherein the CCKrelated satiety signals transmitted to the hindbrain were suggested to be further regulated by leptin action integrated in the Arc as well as neuronal signals from both PVN and LHA (Broberger, 2005; Morton et al., 2005; Maletinska et al., 2008).

CART is widely expressed in the brain and particularly concentrated in the hypothalamus, suggestive of a diverse range of functions. While effective, delivery of ligands via the i.c.v. route is associated with the downside of the simultaneous stimulation of pathways in various parts of the brain, likely contrasting with effects attributable to the activation of specific neuronal populations. One such case are the CART neurons at the Arc, which respond to and are modulated by leptin signals, leading to the activation of selective neurons and associated downstream pathways (Kristensen et al., 1998; Schwartz et al., 2000). It is therefore unsurprising that the observed effects of the i.c.v. injection of substances like CART are not always replicated by targeted delivery of the same peptide into specific nuclei of the hypothalamus. Indeed, several studies have shown that targeting CART into individual hypothalamic nuclei results in revelation of the orexigenic effects of CART, leading to increased food intake and body weight (Abbott et al., 2001; Kong et al., 2003; Smith et al., 2008; Hou et al., 2010). The strongest orexigenic effects were observed by injection of CART into the VMH, DMH and Arc, and a much lesser effect was observed when administered into the PVN, LHA, anterior hypothalamic area, and SO (Abbott et al., 2001; Kong et al., 2003; Smith et al., 2008; Hou et al., 2010) (Table 1). Other effects following Arc and PVN CART delivery such as greater energy expenditure and thermogenic capacity, as indirectly measured by the expression and activity of UCP-1 in brown adipose tissue crucial in thermogenesis, has also been reported (Wang et al., 2000; Kong et al., 2003) (Table 1).

Despite the dependence of endogenous CART expression on nutritional states discussed above, energy states of the animals or dietary options appeared to have little influence over the potency of CART administration-induced feeding stimulation (Abbott et al., 2001; Kong et al., 2003; Smith et al., 2008; Hou et al., 2010). For instance, intra-arcuate delivery of CART resulted in elevated food intake in rodents under both fasted, food-restricted and satiated conditions, subjected to the dietary interventions of either regular chow or HFD (Abbott et al., 2001; Kong et al., 2003; Hou et al., 2010). Intriguingly, the orexigenic effects of CART were exhibited in both non-diabetic normal rats as well as streptozotocin-induced diabetic rats, where the intra-Arc CARTinduced increase in feeding was reproduced under various energy states and dietary treatments (Hou et al., 2010). Similarly, in rats 
receiving chronic overexpression of recombinant CART virally delivered into the PVN, higher cumulative food intake and body weight gain was observed in both groups fed either normal chow or HFD compared to control groups, with more pronounced changes in the HFD group (Smith et al., 2008). Underlying such observations, the appetite-promoting effects of hypothalamic intranuclear CART administration may be attributed to a role of hypothalamic CART in stimulating the release of orexigenic neuropeptides locally (Smith et al., 2008; Hou et al., 2010). This is supported by experiments involving a static incubation system where an increase in the release of NPY- and AgRP-IR but not $\alpha$-MSH-IR was detected in both Arc-containing hypothalamic explants incubated with CART peptide in vitro as well as in PVN-containing hypothalamic explants isolated from animals subjected to intra-PVN CART injection (Smith et al., 2008; Hou et al., 2010). Direct hypothalamic intranuclear CART injection at specific sites, therefore resulted in feeding behaviors opposite to the anorectic effects seen for i.c.v. CART.

The discrepancy between the anorexic effects of CART when injected i.c.v. vs. the predominately orexigenic effects of CART when delivered into specific hypothalamic nuclei suggests that CART expression/function in other brain areas may also be important to the regulation of food intake and energy homeostasis, also suggesting that CART may be involved in both anorexigenic and orexigenic circuits in the CNS (Parker and Bloom, 2012). Other potential areas for CART-mediated anorexic effects include the striatum, which is known to have upregulated CART expression following acute i.p. administration of psychostimulants (Douglass et al., 1995; Fagergren and Hurd, 1999; Hubert and Kuhar, 2008), reduced CART mRNA levels following fasting (Kristensen et al., 1998; Adams et al., 1999; Yang and Shieh, 2005), and has been shown to be involved in the mediation of reward and reinforcement (Koob and Bloom, 1988; Salamone, 1996; Upadhya et al., 2012) as well as the neuronal circuits controlling feeding behavior (Bakshi and Kelley, 1993; Gilbert and Cooper, 1995; Pothos et al., 1995; Stratford et al., 1997; Stratford and Kelley, 1999; Baldo et al., 2002; Yang and Shieh, 2005; Upadhya et al., 2012). Evidence for such a role was gained from experiments in a strain of CCK-1 receptor-deficient obese rats, where a significant reduction in CART immunoreactivity in the Arc was found potentially associated with a diminished anorectic effect of CART peptide compared to lean controls (Abraham et al., 2009). Furthermore, intra-accumbal CART peptide injection has been demonstrated to diminish both basal food consumption and food deprivation-induced feeding (Yang and Shieh, 2005; Jean et al., 2007), as well as potently attenuating the orexigenic effects of the GABA-A agonist muscimol (Yang and Shieh, 2005), albeit some inconsistency across different studies (Jaworski et al., 2008) (Table 1). The antagonistic effects of the GABA system and CART at the Acb were also demonstrated in the neurochemical phenotypes of hypothalamic neurons after the appetite-inducing microinjection of muscimol into the AcbSh, which increased Fos expression in orexin neurons at the perifornical area and NPY neurons at the Arc, while inhibiting that in Arc CART/POMC neurons (Zheng et al., 2003). In a recent study, subcutaneous injection of the GABA-A active neurosteroid ALLO significantly reduced CART immunoreactive cells and fibers in the AcbSh, as well as in other feeding-related hypothalamic nuclei such as the PVN, Arc and LHA (Nakhate et al., 2013). Direct CART administration into the Acb performed by an independent group generated no detectable influence on food reward assessed by food self-administration, yet triggered inhibitory effects on cocaine self-administration, an alternative measure of reward and reinforcement entailing dopaminergic functions (Jaworski et al., 2008).

The anorexia elicited by intra-accumbal CART was more sustainable in freely fed compared to starved animals, highlighting the significance of fuel status on CART function in feeding modulation (Yang and Shieh, 2005). Furthermore, complementary to the overexpression experiments, RNA-interference has been employed to investigate the effects of CART depletion in rodents (Jean et al., 2007; Job and Kuhar, 2012). Tissuespecific CART knockdown in the Acb via intra-accumbal administration of short interfering RNA (siRNA) or short hairpin (shRNA) against CART mRNA induced body weight gain and hyperphagia in fed mice (Jean et al., 2007; Job and Kuhar, 2012), as well as abolishing the anorectic effects of serotonin (5-hydroxytryptamine, 5-HT) 4 receptor (5-HT4R) stimulation as well as 3,4-N-methylenedioxymethamphetamine (MDMA, ecstasy) treatment in starved mice, further denoting the potential role of Acb CART in mediating the appetite suppressant properties in models of anorexia nervosa (Jean et al., 2007).

Despite the body of evidence endorsing the plausibility of the Acb as a site for CART-directed anorexia, the appetiteregulating effects produced by intra-accumbal CART likely represent part of the reward and motivational responses derived from an interaction between CART and the dopaminergic system in the Acb. Multiple lines of evidence have suggested an inhibitory role of endogenous accumbal CART in addictionrelevant behaviors, which are speculated to act in concert with feeding modulation as well as the locomotive effects mediated by the dopaminergic circuits (Kim et al., 2003; Jaworski et al., 2008; Hubert et al., 2010; Job and Kuhar, 2012; Upadhya et al., 2012). For instance, substantial innervations have been described for CART-containing neurons in the ventral pallidum, a key nucleus harboring accumbal efferents, where CART-IR terminals were reported to compose symmetric synapses resembling inhibitory GABAergic synapses (Hubert et al., 2010). Whilst intra-accumbal administration of CART alone produced no effect on locomotor activity, co-injection with cocaine or amphetamine into the Acb inhibited the cocaine-like locomotor effects produced by Acb dopamine microinfusions, both intra-accumbal and intra-pallidal injections of CART peptide led to reduction in cocaine- and amphetamine-induced locomotor activity (Jaworski et al., 2003, 2008; Kim et al., 2003; Hubert et al., 2010). Correspondingly, CART depletion through intra-accumbal CART shRNA increased cocaine-mediated locomotion (Job and Kuhar, 2012), supporting an antagonistic property of Acb CART in the functions of cocaine and other psychostimulants.

The hindbrain, as a region described to convey post-prandial satiety effects to the hypothalamus, has been considered a potential candidate site for CART action (Marty et al., 2007; 
Subhedar et al., 2014). Supporting evidence include the moderate CART expression in terms of both transcript levels and immunoreactivity in caudal brain areas such as the locus coeruleus, NTS, PBN and the inferior olive (Douglass et al., 1995; Koylu et al., 1998), accorded with the increased Fos-IR identified in the NTS and PBN following i.c.v. CART into the LV (Vrang et al., 1999b). Comparable to i.c.v. injections into the LV or $3 \mathrm{~V}$, hindbrain delivery of CART peptide through the 4 th ventricle $(4 \mathrm{~V})$ led to reduction in food intake and body weight in both fed and food-deprived rodents, whilst the hypophagic effects showed no specificity to nutrients from either chow, sucrose or a nutritionally complete liquid diet (Aja et al., 2001b, 2002; Zheng et al., 2001, 2002; Skibicka et al., 2009) (Table 1). Importantly, the extent of feeding inhibition appeared more potent with CART administered into the $4 \mathrm{~V}$ compared with LV injections (Zheng et al., 2001), raising the speculation that the hindbrain may house the key mediator for the hypophagic effects of i.c.v. CART (Aja et al., 2001b). Foundation for the idea involved the postulate that the anorectic effects triggered by forebrain i.c.v. CART indeed reflected the outcome of CART diffusion into hindbrain sites via the cerebrospinal fluid (CSF) (Aja et al., 2001b). Surmised from the CART-IR observed in cell bodies and central terminals of vagal afferent neurons projecting to the GI tract, a potential functional role of CART in meal termination and satiety may effectuate at the level of the brainstem (Broberger et al., 1999; Zheng et al., 2002). In rat, vagotomy caused considerable reduction in CART mRNA expression in several CART fibers in the vagus nerve and viscero-sensory nodose ganglion (Broberger et al., 1999). To verify such proposition, cerebral aqueduct occlusion was performed with an aqueductal plug to interrupt the forebrain-hindbrain CSF flow, and CART was injected into the $3 \mathrm{~V}$ or $4 \mathrm{~V}$ (Aja et al., 2001b) (Table 1). Interestingly, cerebral aqueduct blockage markedly attenuated the anorectic effects of $3 \mathrm{~V}$ CART, whilst suppression of food intake remained unchanged when receiving $4 \mathrm{~V}$ CART injection, signifying the independence of hindbrain CART in producing anorexia (Aja et al., 2001b). In contrast, hindbrain processing may be required or responsible for mediating a hypophagic response following forebrain or interbrain i.c.v. CART, further reinforcing the role of the brainstem in manifesting CART-driven anorectic effects, as concordant with the aforementioned higher potency in feeding inhibition with $4 \mathrm{~V}$ as opposed to forebrain or interbrain i.c.v. CART (Zheng et al., 2001). Specifically, on the assumption that the repressed ingestive behaviors following LV or 3V CART may attribute to hindbrain CART action, the observations resulted from obtrusion of CSF flow could offer a possible explanation for the opposite feeding effects of orexigenic and anorexigenic natures induced by direct hypothalamic subnuclei (Wang et al., 2000; Abbott et al., 2001; Kong et al., 2003; Smith et al., 2008; Hou et al., 2010) vs. hindbrain ventricular (Aja et al., 2001b, 2002; Zheng et al., 2001, 2002; Skibicka et al., 2009) CART administration respectively. Such phenomena promote reevaluation of the authenticity and proposed mechanisms involved in the hypophagia exhibited after forebrain ventricular CART detailed in other studies (Kristensen et al., 1998; Lambert et al., 1998; Vrang et al., 1999b; Larsen et al., 2000; Abbott et al., 2001; Aja et al., 2001a,b).

\section{FUNCTIONAL IMPLICATIONS OF CART DELETION ON ENERGY METABOLISM FROM GENETIC INTERVENTIONS}

In order to gain further insight into the functional consequences of reduced or absent CART expression, several knockout models have been generated and characterized (Asnicar et al., 2001; Couceyro et al., 2005; Elefteriou et al., 2005; Osei-Hyiaman et al., 2005; Wierup et al., 2005; Moffett et al., 2006; Steiner et al., 2006) (Table 2). The phenotypic effects resulting from CART gene targeting approaches have in part shown inconsistency between studies, however, displayed a general trend in promoting positive energy balance. This in overall terms is also similar with results obtained from our novel CART knockout (KO) model, which was generated from a conditional version that was crossed with an oozyte-specific Cre line. Collective evidence regarding the role of CART in energy homeostasis from a few representative studies conducted by independent research groups (Table 2) as well as in-house results will be discussed.

In all models investigated, the expected increase in feeding due to depletion of the anorectic CART peptide was not observed under standard chow feeding conditions. However, when exposed to a high caloric diet, lack of CART led to altered feeding behavior and body weight (Asnicar et al., 2001; Couceyro et al., 2005; Wierup et al., 2005; Moffett et al., 2006). An increase in body weight has also been shown in CART KO mice fed on regular chow, although manifestation of such trait appears to require a longer time frame, where in one study, a statistically significant increase was absent at 17 weeks of age (Asnicar et al., 2001), whilst an independent group adopting the identical mouse model reported notably higher body weight for the knockout mice at 20 weeks (Moffett et al., 2006). In a different CART knockout mouse line, again altered weight was undetectable prior to 40 weeks of age (Couceyro et al., 2005; Wierup et al., 2005). Similarly, when fed a high fat diet, a significantly higher food consumption was observed in the CART KO compared to wild-type (WT) mice (Asnicar et al., 2001), in some but not all studies addressed. Importantly, despite a lack of consistent alteration in food intake, all studies reported an elevated body weight gain in CART knockout animals regardless of dietary options, with an even more prominent effect shown with a high caloric diet (Asnicar et al., 2001; Wierup et al., 2005; Moffett et al., 2006).

Interestingly, fasting-induced food intake experiments in our novel CART KO model suggest that lack of CART may be beneficial for body weight conservation during starvation. In our study, chow-fed CART KO animals showed a slightly lower food consumption compared with WT during a refeeding period following a 24-h fast, yet demonstrated a similar degree and pace of recovery in body weight, implying that less food might be required for returning to the pre-fast weight. On the other hand, the same CART KO mice on HFD experienced a less dramatic drop in body weight upon fasting, and accordingly showed a more effective weight regain to baseline during refeeding. Such improved reactions to food deprivation may be correlated to the observed difference in growth and possibly attributable to events in the interaction between CART and an improved stress response in CART KO mice, consistent with a role of the CART system in stress and anxiety-like responses (Koylu et al., 2000; Stanley et al., 2001, 2004; Kong et al., 2003; Larsen et al., 2003; 


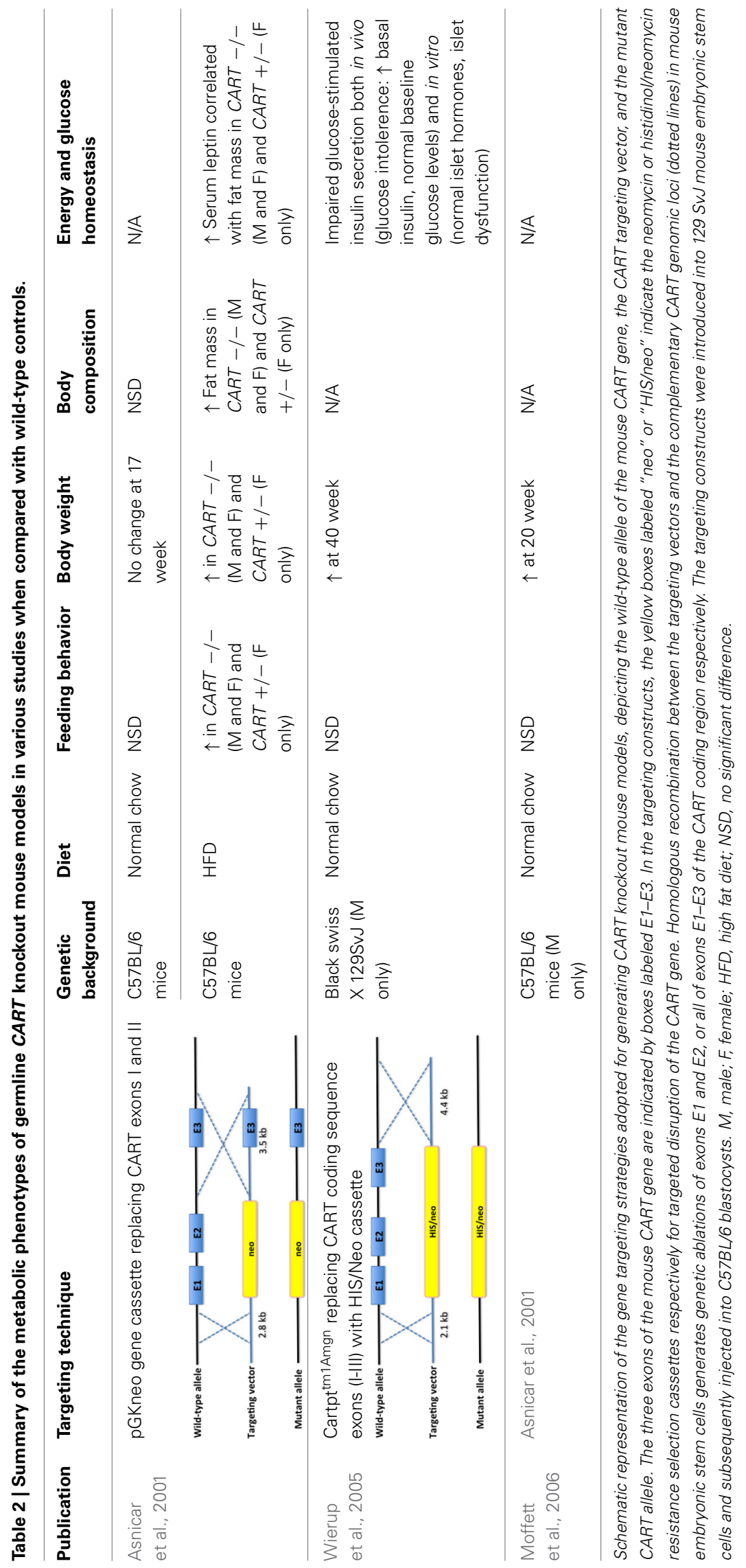


Vrang et al., 2003; Dominguez et al., 2004a; Smith et al., 2004; Gozen et al., 2007; Hunter et al., 2007; Rogge et al., 2008; Nakhate et al., 2011). For example, i.c.v. CART has been reported to substantially influence the plasma levels of various stress hormones, such as adrenocorticotropic hormone and corticosterone (Stanley et al., 2001). Furthermore, anatomical implication has also been provided by the expression of CART transcript and peptide at various levels of the HPA axis as well as other stress-related areas in the CNS (Douglass et al., 1995; Couceyro et al., 1997; Koylu et al., 1997, 1998; Elias et al., 1998; Broberger, 1999; Larsen et al., 2003; Vrang, 2006; Rogge et al., 2008; Nakhate et al., 2011).

Amongst a multitude of potential factors contributing to the enhanced body weight in CART KO models, the gain in fat mass has been considered the most important (Asnicar et al., 2001). This is concordant with results from our novel CART KO model, where body composition analysis by dual-energy X-ray absorptiometry (DXA) revealed a pronounced increase in adiposity independent of diet. The gain in whole body fat mass was further confirmed by tissue dissection showing significantly elevated fat masses in all white adipose tissues, including the inguinal, epididymal, mesenteric and retroperitoneal regions. This also suggests an important function of CART in lipid metabolism, where CART has been linked to inhibition of lipogenesis and stimulation of lipid substrate mobilization and utilization (RohnerJeanrenaud et al., 2002; Wortley et al., 2004; Vasseur et al., 2007; Banke et al., 2013).

In addition to fat mass, lean mass constitutes another major determinant of energy homeostasis that directly influences energy expenditure. As opposed to the increase in fat mass, whole body lean mass of our CART-deficient mice was distinctly lower compared to WT controls regardless of dietary treatments. Similarly, the reduction was consistent across both periods of DXA measurements at 10 and 14 weeks of age. Intriguingly, research investigating the effects of chronic central CART infusion in genetically normal DIO rats reported a diminished body weight gain primarily due to a loss of lean mass (Larsen et al., 2000; Qing and Chen, 2007), while fat mass was unaffected (Qing and Chen, 2007).

Consistency exists between results from our CART KO model and previous studies focusing on the metabolic characterization of CART knockout mice, where no significant difference in total energy expenditure or physical activity could be detected when compared with WT controls regardless of diets (Asnicar et al., 2001; Moffett et al., 2006), even after the correction of the potentially confounding effects of lean mass on energy expenditure. However, overexpression studies have provided indications of both supporting and opposing roles of CART in regulating energy expenditure (Kong et al., 2003; Qing and Chen, 2007). An increase in energy expenditure was suggested in rats subject to chronic overexpression of CART through intra-arcuate targeted gene transfer, where the animals showed exaggerated weight loss and a downregulation of endogenous arcuate CART mRNA levels upon fasting and food restriction (Kong et al., 2003). Despite discordance between various animal studies, evidence exists for the involvement of CART in the regulation of energy expenditure and body weight in humans (Challis et al., 2000; del Giudice et al., 2001; Yamada et al., 2002; Dominguez et al., 2004a; Guerardel et al., 2005; Yanik et al., 2006; Rigoli et al., 2010). Specifically, a missense mutation in the pro-CART transcripts was discovered to co-segregate with a severe obese phenotype and was also associated with decreased resting energy expenditure in members of an Italian family over three generations (del Giudice et al., 2001; Dominguez et al., 2004a; Yanik et al., 2006).

In spite of a lack of direct indication endorsing a function of CART in modulating energy expenditure, comparing the respiratory exchange ratio (RER) between CART knockout animals and WT counterparts may shed light on any potential effects of CART ablation on energy metabolism through the fuel source preferences. Although no measurable difference was described in knockout animals in the respiratory quotient derived from RER as reported by previous studies (Asnicar et al., 2001; Moffett et al., 2006), a notably lower RER has been detected in our new CART knockout mice. Consistency in the lower RER particularly during the dark photoperiod was shown across both nutritional statuses, signifying that fat was preferentially metabolized over carbohydrates to supply energy for the body. A possible explanation for this could be the higher fat content in knockout animals, which may lead to the predominant fuel source based on the relative higher availability of fat than carbohydrates. On the other hand, a suppressed average respiratory quotient was demonstrated in both normal and DIO rats chronically overexpressing central CART compared to vehicle-treated controls (Rohner-Jeanrenaud et al., 2002; Qing and Chen, 2007). The reduction was exaggerated during the dark phase, under both regular feeding and fastingrefeeding conditions, indicating a stimulatory role of CART in promoting lipid oxidation and limiting fat storage, hence inhibiting excessive body fat accrual (Rohner-Jeanrenaud et al., 2002; Wortley et al., 2004; Qing and Chen, 2007).

Taken together, results from the literature as well as in-house studies of CART knockout models generally support the property of CART as a satiety factor and an anorexigenic signal in the brain, as evident in the elevation in body weight gain attributable mostly to the increased fat mass consistent across studies, although controversy exists for the corresponding food intake data. As for the aspect of energy intake, RER was demonstrated to be reduced both under the conditions of CART overexpression and ablation, suggesting fat was metabolized as the primary fuel for energy supply. A possible reason could be that although CART may intrinsically promote the utilization of fat as the predominant fuel source for reducing energy intake, the effectiveness of CART deletion on the disturbance of lipid metabolism hence accumulation of adiposity may have surmounted the simultaneous CART deficiency-induced enhancement of energy intake, resulting in a net reduction in RER based on the readily available fat depots.

\section{ROLES OF CART IN HUMAN}

As introduced earlier, evolutionary conservation has been demonstrated for CART in the neuroendocrine system across various mammalian species in the contexts of isoform structure, expression distribution pattern as well as functional implications, including a role of CART in the regulation of energy balance in human (Hager et al., 1998; Challis et al., 2000; del Giudice et al., 2001; Yamada et al., 2002; Dominguez et al., 2004a; Guerardel et al., 2005; Yanik et al., 2006; Rigoli et al., 2010). First, a genomewide scan for human obesity-susceptibility loci in obese French 
Caucasian families (Hager et al., 1998) revealed a clear linkage to the chromosomal locus of $5 q 13.2$ where the human CART gene is encoded (Table 3). Respectively, the expression of CART transcripts and peptides has been characterized in various hypothalamic areas involved in appetite control (Charnay et al., 1999; Elias et al., 2001; Menyhért et al., 2007), as well as in the subcutaneous and visceral white adipose tissues central to the moderation of lipid homeostasis (Vasseur et al., 2007; Banke et al., 2013). Intriguingly, the aforementioned anatomical-functional implications provided by the expression patterns of CART in the human infundibular nucleus, which demonstrated colocalization with the orexigenic NPY/AgRP and segregation from the anorexigenic POMC neurons, had rendered a primary anorectic role of CART appealable (Menyhért et al., 2007).

In human, alterations in CART have been associated with reduced metabolic rate, hyperphagia, obesity and elevated incidence of type II diabetes (Banke et al., 2013) (Table 3). For example, a Leu34Phe missense mutation in human proCART was discovered in obese members of an Italian family across three generations to affect post-translational processing, which coincided with CART peptide deficiency in the sera and reduced resting energy expenditure, ultimately leading to hyperphagia and severe early-onset obesity (del Giudice et al., 2001; Dominguez et al., 2004a; Yanik et al., 2006). In brief, the mutation was identified to neighbor a cluster of basic amino acids, hence presupposed to influence the specific processing of the proCART (1-89) in generating the biologically active CART I (42-89) and CART II (49-89) peptides (Kuhar and Yoho, 1999; Thim et al., 1999; del Giudice et al., 2001; Dominguez et al., 2004a). To simulate cellular effects of the mutation, subsequent investigations transfected human CART cDNA constructs representing either the wild-type or the mutant into corticotropic AtT-20 cells, a mouse pituitary-derived cell line often used for studying peptide processing and, more importantly, is known to express and process CART peptides (Dominguez et al., 2004a). Notably, in addition to reduced CART peptide levels in cells transfected with the mutated cDNA compared with controls, expression of the mutated proCART was also described to be mis-sorted, poorly processed and secreted, thus disarranging the cellular distribution of CART as a whole (Dominguez et al., 2004a). Other than discoveries that addressed the potentially crucial role of protein biosynthesis in the development of obesity, the majority of the studies directed at the association between CART and obesity focused on polymorphisms in CART within populations.

Polymorphism studies in the CART gene conducted worldwide have established substantial linkage between a few specific single nucleotide polymorphisms (SNPs) to obesity (del Giudice et al., 2001; Yamada et al., 2002; Guerardel et al., 2005; Rigoli et al., 2010) (Table 3). For instance, a family-based association study of 133 Italian trios has identified significantly higher allele frequencies of the $1475 \mathrm{~A}>\mathrm{G} \mathrm{SNP}$ in the CART gene in overweight and obese children compared to non-obese unrelated controls consisting of both adults and children, while preferential transmission of the allele to overweight or obese children from heterozygous parents was predicted (Rigoli et al., 2010). In another Caucasian population, 292 French morbidly obese subjects were recruited for sequence variability screen in the CART gene, where a few
SNPs residing in the promoter region, with SNP-3608T $>C$ in particular, were suggested by haplotype analysis to prominently contribute to the genetic risk for obesity (Guerardel et al., 2005). The proposed association was further strengthened by the high prevalence of the specific allele in an expanded genotyping study, with additional populations of European Caucasian origin comprising 619 moderately obese French subjects and 385 morbidly obese Swiss subjects (Guerardel et al., 2005). Extended on the genetic studies, plausible functional effects of the SNP were also investigated by electrophoretic mobility shift assays in cellular system, where modulation of nuclear protein binding affinity was demonstrated to potentially correlate with the obesity phenotype (Guerardel et al., 2005). Besides Caucasians, a sequencing study in 528 Japanese subjects revealed a high level of polymorphisms in the $5^{\prime}$-flanking region of the CART gene housing the putative promoter region, wherein specific polymorphic sites or variants in linkage disequilibrium with each other were identified to associate with genetic predisposition to obesity (Yamada et al., 2002).

As mentioned, CART has recently been defined as a component of adipocytes involved in lipid substrate utilization in both human and rodents (Banke et al., 2013). Investigation in a large Caucasian population of approximately 1000 subjects in the United Kingdom identified two common polymorphisms in the $3^{\prime}$ - untranslated region of CART, that were implicated to interfere with fat distribution and contribute to dyslipidaemia (Challis et al., 2000; Rogge et al., 2008) (Table 3). Despite a lack of correlation or consistent association with obesity through systematic mutational analysis (Lambert et al., 1998; Challis et al., 2000; Okumura et al., 2000; Rogge et al., 2008), a particular genetic variant $1475 \mathrm{~A}>\mathrm{G}$ among the polymorphisms was illustrated to significantly affect waist-to-hip ratio as well as the levels of plasma insulin and triglycerides (Challis et al., 2000), suggesting a putative pivotal role of CART in glucose- and lipid-homeostasis. Consolidation of the proposition has been illustrated in subsequent haplotypic study in a general population of 840 subjects from northern France (Vasseur et al., 2007), a continuum from the former French project on CART promoter SNPs (Guerardel et al., 2005), where three of the previously identified SNPs were described to affect plasma low-density lipoprotein-cholesterol level and consequently associated with cholesterol metabolism and atherogenicity (Guerardel et al., 2005; Vasseur et al., 2007). Specifically, the functional SNP-3808C $>$ T was of particular interest, as plasma lipid profile traits protective against atherogenesis were displayed in cases bearing the allele, exemplifying the clinical potentials of CART in lipid metabolism and atherogenesis (Vasseur et al., 2007; Banke et al., 2013).

Taken together, human studies based principally on genetic polymorphisms have provided evidence promoting a role of CART in body weight regulation in humans. Altered CART expression has generally been associated with an elevated genetic predisposition to overweight and obesity, indirectly substantiating the anorexigenic nature of the peptide, although results from the literature show both anorexigenic and orexigenic properties of CART in animal studies. It is also noteworthy to address the plausible challenges imposed on the translatability of results obtained from animal models to the human system, considering the discernible difference in the anatomy of central CART-containing 


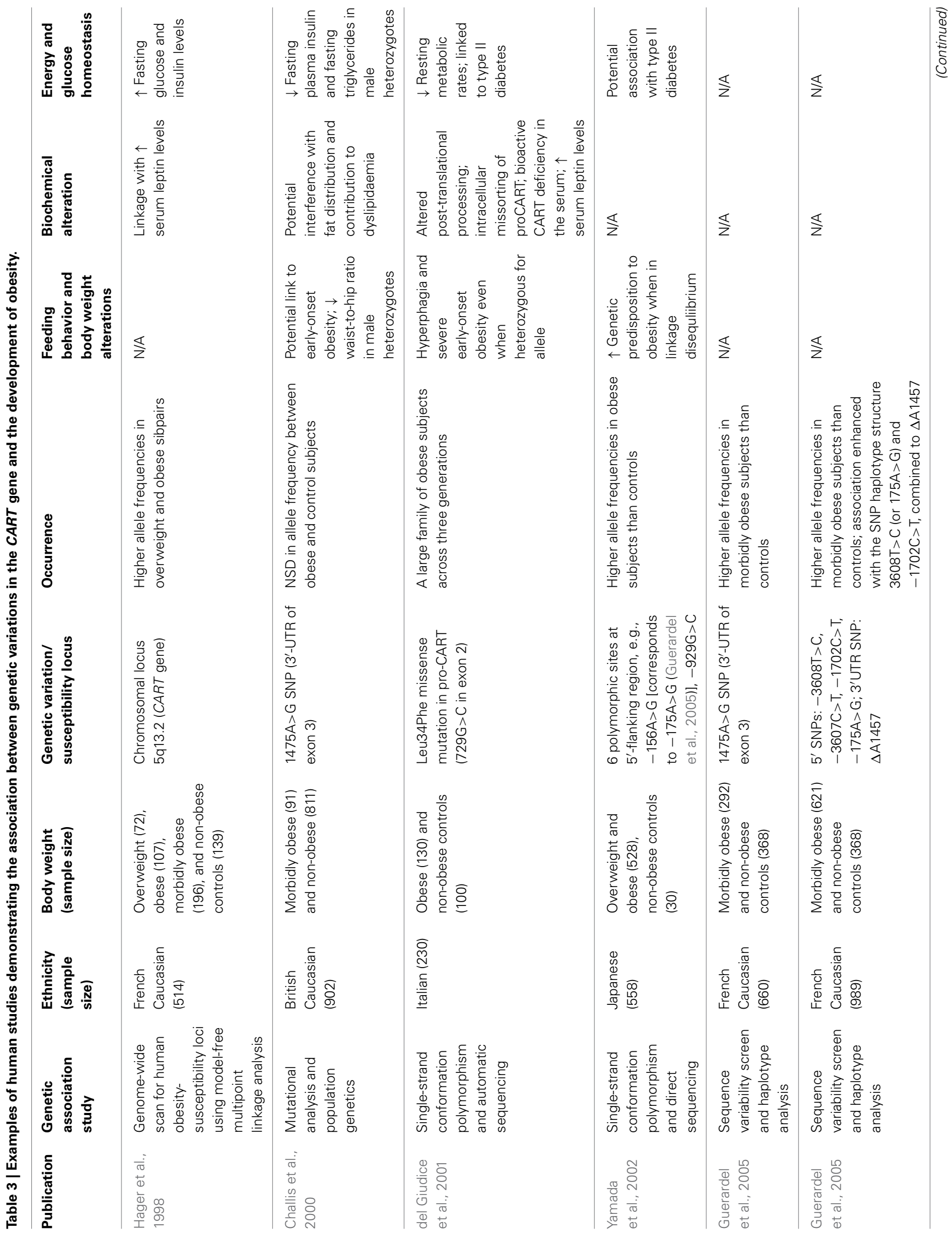




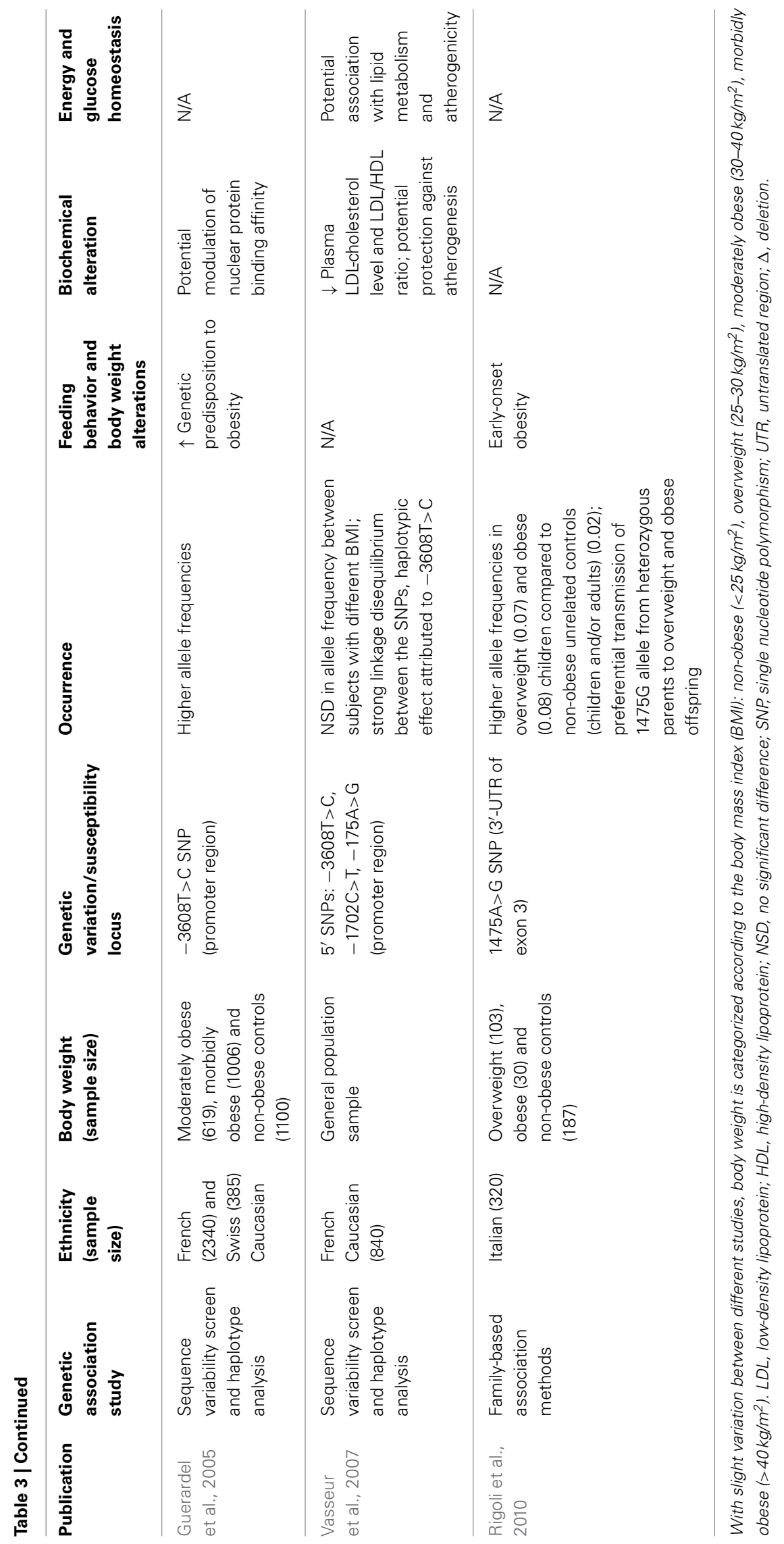


neurons between the two, as discussed above. Furthermore, although overall support has been gained for the hypothesis that inherited variations in CART could influence the development of obesity, such genetic linkage was absent for some other sequence variants detected within the gene, where the polymorphisms have been speculated as insufficient to disturb the peptide structure or create topological and conformational changes in the protein that would ultimately affect the functional activity of the peptide (Echwald et al., 1999; Walder et al., 2000; Rogge et al., 2008). Indeed, recent studies conducting an alanine scan for assessing the importance of the structure-activity relationship of CART demonstrated the dependence of anorexigenic potency on individual disulfide bridges in the peptide (Maixnerova et al., 2007; Maletinska et al., 2007; Blechova et al., 2013). To elucidate the contribution of specific disulfide bridges to maintaining the stability and biological function of CART, analogs with only one or two among the three disulfide bridges in the intact peptide were synthesized, with which binding activities as well as metabolic effects were measured in both cell and animal systems (Maixnerova et al., 2007). Intriguingly, results from binding experiments in PC12 rat pheochromocytoma cells (Maixnerova et al., 2007; Maletinska et al., 2007; Lin et al., 2011) indicated that the preservation of two particular disulfide bridges as well as the full-length peptide was imperative for biological activity, where high affinity of the analog to PC12 cells in both states of native phenotype and differentiated into neurons was measured (Blechova et al., 2013). In mice subjected to i.c.v. administration of the same analog, strong and long-lasting anorexigenic potency was exhibited during food consumption and behavioral tests, further purporting that one particular disulfide bridge could be omitted without a loss of bioactive function (Blechova et al., 2013).

In summary, the familial nature of obesity is well-established to be interrelated with a prominent genetic component. The CART system has been evident to constitute a dominant player in feeding control, body weight regulation and energy metabolism, hence a promising candidate for the development of anti-obesity therapeutics. Respectively, population genetics have revealed the potential contributions of polymorphisms in the CART gene to abnormalities in feeding and body weight control, where effects on interactions between the transcription factors and regulatory elements binding to the polymorphic sites may exert phenotypic influence. However, elucidating the mechanisms of CART action as well as investigating and replicating the fine genetic mapping in further populations will be essential for unraveling the authentic role of CART in energy homeostasis and understanding obesity.

\section{CONCLUSION}

In conclusion, the widely adopted role of CART in the regulation of energy homeostasis has been summarized in this review from the perspectives of genetic and transcriptional associations, anatomical-functional correlation, pharmacological and genetic intervention studies in animal models, as well as implications from sequence variability in human. Nevertheless, the lack of a known CART receptor(s) and specific antagonists, continues to constitute the major challenge in understanding the underlying mechanisms by which CART exerts effects on feeding and neuroendocrine regulation.

The physiological importance of CART is endorsed by the evolutionarily conserved expression patterns in the brain as well as the periphery at regions associated with energy balance, inferring structural hence functional conservation in glucose sensing, lipogenesis regulation and ultimately the control of feeding behavior. The resultant integrated outcome on metabolic modulation also represents the neuronal crosstalk involving similar neuromodulatory peptides between central CART-interfered pathways residing at the hypothalamic and brainstem neurons as well as via the hypothalamic-pituitary-adrenal axis. In comparison with CART in the brain, functional roles of peripheral CART are less established, with indeterminate modes of action speculated to entail either a local independent response, or synergistic effects with central CART.

Overexpression of central CART through i.c.v. injections at either the forebrain (LV), interbrain $(3 \mathrm{~V})$ or hindbrain $(4 \mathrm{~V})$ areas has conformed to an anorexigenic role of CART, while the appetite-promoting effects of CART administered into specific neuronal targets may be attributed to a role of hypothalamic CART in stimulating the local release of orexigenic neuropeptides in a hypothalamic nucleus-specific manner. The discrepancy in anorexigenic and orexigenic circuitry highlights the major pitfall of non-specific widespread effects associated with i.c.v. ligand delivery, and was recognized through the efforts to identify potential sites for CART action following the analysis of Fos expression pattern representative of i.c.v. CART-induced neuronal activities. Candidate sites that may house the key mediator for the hypophagic effects of i.c.v. CART primarily reside in various feeding-related areas, including major hypothalamic nuclei, specific brainstem structures, and the Acb of the cerebral striatum. The appetite-inhibiting and -promoting effects produced by intra-accumbal CART and CART siRNA respectively reflect a concerted response from the CART-dopaminergic system interaction within the Acb, hence the observed feeding modulation and locomotive effects were likely perplexed by the inherent reward and motivation pathway. Several hindbrain areas are of particular interest as alternative brain regions for CART-induced anorexic effects, owing to the well-described role of the hindbrain in conveying post-prandial satiety effects to the hypothalamus, consonant with the indicated relation between CART and vagallymediated gastrointestinal satiety.

In parallel with overexpression approaches, independent research groups have adopted genetic ablation to generate several germline CART knockout murine models, to determine effects of CART depletion on feeding behavior and metabolism. General consistency has been demonstrated between results from the literature and in-house data from our novel CART KO model, supporting CART as a satiety factor. Collectively, the phenotypic effects of CART deficiency from birth, although inconsistent across studies, display promotion toward positive energy balance. Extended findings stemming from our novel $\mathrm{KO}$ model also denote that CART deficiency may confer an advantage in body weight conservation during starvation, potentially associated with an improved stress response attributable to an altered anxiety-related cascade involving the CART system. 
Both gene knockout and overexpression studies of CART have consolidated the stimulatory role of CART in promoting lipid oxidation and inhibiting fat accrual. As discussed above, despite the widely documented anorectic evidence of CART, possibility of an orexigenic role is indisputable. Under certain circumstances, such postulation may provide explanation for the inconsistent or lack of marked phenotypes in terms of energy balance observed in germline CART knockout animals, as well as conditional, developmental stage, or whole brain CART knockout models. Nevertheless, temporal or tissue-specific genetic ablation serves an invaluable means to minimize common pitfalls associated with a germline knockout strategy, such as any secondary effects or compensatory mechanisms during development.

In human, the expression of CART transcripts and peptides has been characterized in various hypothalamic areas involved in appetite control and lipid homeostasis. From the perspective of population genetics, genome-wide study of human obesitysusceptibility loci revealed linkage to a locus harboring the human $C A R T$ gene, whereas mutation profiling has associated alterations in CART with reduced metabolic rate and resting energy expenditure, hyperphagia, obesity and elevated incidence of type II diabetes. Intriguingly, whilst a role of CART in regulating energy expenditure remains equivocal in overexpression studies and considered discordant in gene deletion approach in animal models, mutation screening in humans has consolidated the involvement of CART in the modulation of energy expenditure, body weight and dyslipidaemia.

To elucidate the underlying cellular mechanisms, functional effects of mutations and polymorphisms that were linked to the development of obesity were investigated. The sequence alterations of interests were described to potentially interfere with the post-translational processing of CART, leading to defective protein biosynthesis and deranged cellular distribution of the peptide, while modulation in the nuclear protein binding affinity was also reported to attenuate biological activity. Despite the plausible challenges imposed on the translatability of principal observations from animal models to the less well-documented human system, aberrations in CART have been demonstrated in human studies to promote positive energy balance, endorsing a primary anorectic role of CART.

In sum, the CART system remains a dominant player in the regulation of feeding, body weight and energy metabolism, hence a promising candidate for the development of anti-obesity therapeutics. However, elucidating the underlying mechanisms of CART action, developing relevant pharmacological tools and understanding the nature of the endogenous CART receptor(s), remains crucial in unraveling the functional role of CART in energy homeostasis and obesity.

\section{REFERENCES}

Abbott, C. R., Rossi, M., Wren, A. M., Murphy, K. G., Kennedy, A. R., Stanley, S. A., et al. (2001). Evidence of an orexigenic role for cocaine- and amphetamineregulated transcript after administration into discrete hypothalamic nuclei. Endocrinology 142, 3457-3463. doi: 10.1210/endo.142.8.8304

Abraham, H., Covasa, M., and Hajnal, A. (2009). Cocaine- and amphetamineregulated transcript peptide immunoreactivity in the brain of the CCK1 receptor deficient obese OLETF rat. Exp. Brain Res. 196, 545-556. doi: 10.1007/s00221-009-1885-3

Adam, C. L., Archer, Z. A., Findlay, P. A., Thomas, L., and Marie, M. (2002). Hypothalamic gene expression in sheep for cocaine- and amphetamine-regulated transcript, pro-opiomelanocortin, neuropeptide Y, agouti-related peptide and leptin receptor and responses to negative energy balance. Neuroendocrinology 75, 250-256. doi: 10.1159/000054716

Adams, L. D., Gong, W., Dall Vechia, S., Hunter, R. G., and Kuhar, M. J. (1999). CART: from gene to function. Brain Res. 848, 137-140. doi: 10.1016/S00068993(99)01907-1

Ahima, R. S., and Hileman, S. M. (2000). Postnatal regulation of hypothalamic neuropeptide expression by leptin: implications for energy balance and body weight regulation. Regul. Pept. 92, 1-7. doi: 10.1016/S0167-0115(00)00142-7

Ahima, R. S., Kelly, J., Elmquist, J. K., and Flier, J. S. (1999). Distinct physiologic and neuronal responses to decreased leptin and mild hyperleptinemia. Endocrinology 140, 4923-4931.

Aja, S., Robinson, B. M., Mills, K. J., Ladenheim, E. E., and Moran, T. H. (2002). Fourth ventricular CART reduces food and water intake and produces a conditioned taste aversion in rats. Behav. Neurosci. 116, 918-921. doi: 10.1037/0735-7044.116.5.918

Aja, S., Sahandy, S., Ladenheim, E. E., Schwartz, G. J., and Moran, T. H. (2001b). Intracerebroventricular CART peptide reduces food intake and alters motor behavior at a hindbrain site. Am. J. Physiol. Regul. Integr. Comp. Physiol. 281, R1862-R1867.

Aja, S., Schwartz, G. J., Kuhar, M. J., and Moran, T. H. (2001a). Intracerebroventricular CART peptide reduces rat ingestive behavior and alters licking microstructure. Am. J. Physiol. Regul. Integr. Comp. Physiol. 280, R1613-R1619.

Albertson, D. N., Pruetz, B., Schmidt, C. J., Kuhn, D. M., Kapatos, G., and Bannon, M. J. (2004). Gene expression profile of the nucleus accumbens of human cocaine abusers: evidence for dysregulation of myelin. J. Neurochem. 88, 1211-1219. doi: 10.1046/j.1471-4159.2003.02247.x

Asakawa, A., Inui, A., Yuzuriha, H., Nagata, T., Kaga, T., Ueno, N., et al. (2001). Cocaine-Amphetamine-regulated transcript influences energy metabolism, anxiety and gastric emptying in mice. Horm. Metab. Res. 33, 554-558. doi: 10.1055/s-2001-17205

Asnicar, M. A., Smith, D. P., Yang, D. D., Heiman, M. L., Fox, N., Chen, Y.-F., et al. (2001). Absence of cocaine- and amphetamine-regulated transcript results in obesity in mice fed a high caloric diet. Endocrinology 142, 4394-4400. doi: 10.1210/endo.142.10.8416

Bagnol, D., Lu, X.-Y., Kaelin, C. B., Day, H. E. W., Ollmann, M., Gantz, I., et al. (1999). Anatomy of an endogenous antagonist: relationship between agouti-related protein and proopiomelanocortin in brain. J. Neurosci. 19, RC26.

Bakshi, V. P., and Kelley, A. E. (1993). Feeding induced by opioid stimulation of the ventral striatum: role of opiate receptor subtypes. J. Pharmacol. Exp. Ther. 265, 1253-1260.

Baldo, B. A., Sadeghian, K., Basso, A. M., and Kelley, A. E. (2002). Effects of selective dopamine D1 or D2 receptor blockade within nucleus accumbens subregions on ingestive behavior and associated motor activity. Behav. Brain Res. 137, 165-177. doi: 10.1016/S0166-4328(02)00293-0

Balkan, B., Koylu, E. O., Kuhar, M. J., and Pogun, S. (2001). The effect of adrenalectomy on cocaine and amphetamine-regulated transcript (CART) expression in the hypothalamic nuclei of the rat. Brain Res. 917, 15-20. doi: 10.1016/S00068993(01)02899-2

Banke, E., Riva, M., Shcherbina, L., Wierup, N., and Degerman, E. (2013). Cocaine- and amphetamine-regulated transcript is expressed in adipocytes and regulate lipid- and glucose homeostasis. Regul. Pept. 182, 35-40. doi: 10.1016/j.regpep.2012.12.011

Bannon, A. W., Seda, J., Carmouche, M., Francis, J. M., Jarosinski, M. A., and Douglass, J. (2001). Multiple behavioral effects of cocaine- and amphetamineregulated transcript (CART) peptides in mice: CART 42-89 and CART 49-89 differ in potency and activity. J. Pharmacol. Exp. Ther. 299, 1021-1026.

Barrachina, M. A. D., Martínez, V., Wang, L., Wei, J. Y., and Taché, Y. (1997). Synergistic interaction between leptin and cholecystokinin to reduce short-term food intake in leanĆ mice. Proc. Natl. Acad. Sci. U.S.A. 94, 10455-10460. doi: 10.1073/pnas.94.19.10455

Barsh, G. S., and Schwartz, M. W. (2002). Genetic approaches to studying energy balance: perception and integration. Nat. Rev. Genet. 3, 589-600. doi: 10.1038/ nrg862

Berthoud, H.-R. (2002). Multiple neural systems controlling food intake and body weight. Neurosci. Biobehav. Rev. 26, 393-428. doi: 10.1016/S01497634(02)00014-3

Blechova, M., Nagelova, V., Zakova, L., Demianova, Z., Zelezna, B., and Maletinska, L. (2013). New analogs of the CART peptide with anorexigenic 
potency: the importance of individual disulfide bridges. Peptides 39, 138-144. doi: 10.1016/j.peptides.2012.09.033

Broberger, C. (1999). Hypothalamic cocaine- and amphetamine-regulated transcript (CART) neurons: histochemical relationship to thyrotropin-releasing hormone, melanin-concentrating hormone, orexin/hypocretin and neuropeptide Y. Brain Res. 848, 101-113. doi: 10.1016/S0006-8993(99)01977-0

Broberger, C. (2005). Brain regulation of food intake and appetite: molecules and networks. J. Intern. Med. 258, 301-327. doi: 10.1111/j.1365-2796.2005.01553.x

Broberger, C., Holmberg, K., Kuhar, M. J., and Hökfelt, T. (1999). Cocaine- and amphetamine-regulated transcript in the rat vagus nerve: a putative mediator of cholecystokinin-induced satiety. Proc. Natl. Acad. Sci. U.S.A. 96, 13506-13511. doi: 10.1073/pnas.96.23.13506

Butler, A. A., Kesteson, R. A., Khong, K., Cullen, M. J., Pelleymounter, M. A., Dekoning, J., et al. (2000). A unique metalolic sysdrone causes obesity in the melanocortin-3 receptor-deficient mouse. Endocrinology 141, 3518-3521. doi: 10.1210/endo.141.9.7791

Cavalcante, J. C., Cândido, P. L., Sita, L. V., do Nascimento, E. S. Jr., Cavalcante, J. D. S., de Oliveira Costa, M. S. M., et al. (2011). Comparative distribution of cocaine- and amphetamine-regulated transcript (CART) in the hypothalamus of the capuchin monkey (Cebus apella) and the common marmoset (Callithrix jacchus). Brain Res. 1425, 47-61. doi: 10.1016/j.brainres.2011.09.020

Challis, B. G., Yeo, G. S., Farooqi, I. S., Luan, J., Aminian, S., Halsall, D. J., et al. (2000). The CART gene and human obesity: mutational analysis and population genetics. Diabetes 49, 872-875. doi: 10.2337/diabetes.49.5.872

Charnay, Y., Perrin, C., Vallet, P. G., Greggio, B., Kovari, E., and Bouras, C. (1999). Mapping of cocaine and amphetamine regulated transcript (CART) mRNA expression in the hypothalamus of elderly human. J. Chem. Neuroanat. 17, 123-128. doi: 10.1016/S0891-0618(99)00028-9

Chen, A. S., Marsh, D. J., Trumbauer, M. E., Frazier, E. G., Guan, X.-M., Yu, H., et al. (2000). Inactivation of the mouse melanocortin-3 receptor results in increased fat mass and reduced lean body mass. Nat. Genet. 26, 97-102. doi: $10.1038 / 79254$

Chronwall, B. M. (1985). Anatomy and physiology of the neuroendocrine arcuate nucleus. Peptides 6(Suppl. 2), 1-11. doi: 10.1016/0196-9781(85)90128-7

Couceyro, P., Paquet, M., Koylu, E., Kuhar, M., and Smith, Y. (1998). Cocaineand amphetamine-regulated transcript (CART) peptide immunoreactivity in myenteric plexus neurons of the rat ileum and co-localization with choline acetyltransferase. Synapse 30, 1-8.

Couceyro, P. R., Evans, C., McKinzie, A., Mitchell, D., Dube, M., Hagshenas, L., et al. (2005). Cocaine- and Amphetamine-Regulated Transcript (CART) Peptides Modulate the Locomotor and Motivational Properties of Psychostimulants. J. Pharmacol. Exp. Ther. 315, 1091-1100. doi: 10.1124/jpet.105.091678

Couceyro, P. R., Koylu, E. O., and Kuhar, M. J. (1997). Further studies on the anatomical distribution of CART by in situ hybridization. J. Chem. Neuroanat. 12, 229-241. doi: 10.1016/S0891-0618(97)00212-3

Cowley, M. A., Smart, J. L., Rubinstein, M., Cerdan, M. G., Diano, S., Horvath, T. L., et al. (2001). Leptin activates anorexigenic POMC neurons through a neural network in the arcuate nucleus. Nature 411, 480-484. doi: 10.1038/35078085

Cowley, M. A., Smith, R. G., Diano, S., Tschöp, M., Pronchuk, N., and Grove, K. L. et al. (2003). The distribution and mechanism of action of ghrelin in the CNS demonstrates a novel hypothalamic circuit regulating energy homeostasis. Neuron 37, 649-661. doi: 10.1016/S0896-6273(03)00063-1

Crawley, J. N., and Corwin, R. L. (1994). Biological actions of cholecystokinin. Peptides 15, 731-755. doi: 10.1016/0196-9781(94)90104-X

Crawley, J. N., Fiske, S. M., Durieux, C., Derrien, M., and Roques, B. P. (1991). Centrally administered cholecystokinin suppresses feeding through a peripheral-type receptor mechanism. J. Pharmacol. Exp. Ther. 257, 1076-1080.

de Lartigue, G., Dimaline, R., Varro, A., and Dockray, G. J. (2007). Cocaine- and amphetamine-regulated transcript: stimulation of expression in rat vagal afferent neurons by cholecystokinin and suppression by ghrelin. J. Neurosci. 27, 2876-2882. doi: 10.1523/JNEUROSCI.5508-06.2007

de Lartigue, G., Dimaline, R., Varro, A., Raybould, H., De La Serre, C. B., and Dockray, G. J. (2010). Cocaine- and amphetamine-regulated transcript mediates the actions of cholecystokinin on rat vagal afferent neurons. Gastroenterology 138, 1479-1490. doi: 10.1053/j.gastro.2009.10.034

de Lecea, L., Kilduff, T. S., Peyron, C., Gao, X.-B., Foye, P. E., Danielson, P. E., et al. (1998). The hypocretins: hypothalamus-specific peptides with neuroexcitatory activity. Proc. Natl. Acad. Sci. U.S.A. 95, 322-327. doi: 10.1073/pnas.95.1.322 del Giudice, E., Santoro, N., Cirillo, G., D’Urso, L., Di Toro, R., and Perrone, L. (2001). Mutational screening of the CART gene in obese children: identifying a mutation (Leu34Phe) associated with reduced resting energy expenditure and cosegregating with obesity phenotype in a large family. Diabetes 50, 2157-2160. doi: 10.2337/diabetes.50.9.2157

Dey, A., Xhu, X., Carroll, R., Turck, C., Stein, J., and Steiner, D. (2003). Biological processing of the cocaine and amphetamine-regulated transcript precursors by prohormone convertases, PC2 and PC1/3. J. Biol. Chem. 278, 15007-15014. doi: 10.1074/jbc.M212128200

Dominguez, G. (2006). The CART gene: structure and regulation. Peptides 27, 1913-1918. doi: 10.1016/j.peptides.2006.01.025

Dominguez, G., del Giudice, E. M., and Kuhar, M. J. (2004a). CART peptide levels are altered by a mutation associated with obesity at codon 34. Mol. Psychiatry 9, 1065-1066. doi: 10.1038/sj.mp.4001578

Dominguez, G., Vicentic, A., Del Giudice, E. M., Jaworski, J., Hunter, R. G., and Kuhar, M. J. (2004b). CART peptides: modulators of mesolimbic dopamine, feeding, and stress. Ann. N.Y. Acad. Sci. 1025, 363-369. doi: 10.1196/annals.1316.044

Dong, W., Seidel, B., Marcinkiewicz, M., Chrétien, M., Seidah, N. G., and Day, R. (1997). Cellular localization of the prohormone convertases in the hypothalamic paraventricular and supraoptic nuclei: selective regulation of pcl in corticotrophin-releasing hormone parvocellular neurons mediated by glucocorticoids. J. Neurosci. 17, 563-575.

Douglass, J., and Daoud, S. (1996). Characterization of the human cDNA and genomic DNA encoding CART: a cocaine- and amphetamine-regulated transcript. Gene 169, 241-245. doi: 10.1016/0378-1119(96)88651-3

Douglass, J., McKinzie, A., and Couceyro, P. (1995). PCR differential display identifies a rat brain mRNA that is transcriptionally regulated by cocaine and amphetamine. J. Neurosci. 15, 2471-2481.

Dragunow, M., and Faull, R. (1989). The use of c-fos as a metabolic marker in neuronal pathway tracing. J. Neurosci. Methods 29, 261-265. doi: 10.1016/01650270(89)90150-7

Dun, N., Dun, S., Wong, P., Yang, J., and Chang, J. (2000). Cocaine- and amphetamine-regulated transcript peptide in the rat epididymis: an immunohistochemical and electrophysiological study. Biol. Reprod. 63, 1518-1524. doi: 10.1095/biolreprod63.5.1518

Dun, S. L., Castellino, S. J., Yang, J., Chang, J. K., and Dun, N. J. (2001) Cocaine- and amphetamine-regulated transcript peptide-immunoreactivity in dorsal motor nucleus of the vagus neurons of immature rats. Dev. Brain Res. 131, 93-102. doi: 10.1016/S0165-3806(01)00267-X

Echwald, S. M., Sorensen, T. I., Andersen, T., Hansen, C., Tommerup, N., and Pedersen, O. (1999). Sequence variants in the human cocaine and amphetamine-regulated transcript (CART) gene in subjects with early onset obesity. Obes. Res. 7, 532-536. doi: 10.1002/j.1550-8528.1999.tb00710.x

Edwards, C. M. B., Abbott, C. R., Sunter, D., Kim, M.-S., Dakin, C. L., Murphy, K. G., et al. (2000). Cocaine- and amphetamine-regulated transcript, glucagonlike peptide- 1 and corticotrophin releasing factor inhibit feeding via agoutirelated protein independent pathways in the rat. Brain Res. 866, 128-134. doi: 10.1016/S0006-8993(00)02257-5

Ekblad, E. (2006). CART in the enteric nervous system. Peptides 27, 2024-2030. doi: 10.1016/j.peptides.2005.12.015

Ekblad, E., Kuhar, M., Wierup, N., and Sundler, F. (2003). Cocaine- and amphetamine-regulated transcript: distribution and function in rat gastrointestinal tract. Neurogastroenterol. Motil. 15, 545-557. doi: 10.1046/j.13652982.2003.00437.x

Elefteriou, F., Ahn, J., Takeda, S., Starbuck, M., Yang, X., Liu, X., et al. (2005). Leptin regulation of bone resorption by the sympathetic nervous system and CART. Nature 434, 514-520. doi: 10.1038/nature03398

Elias, C. F., Aschkenasi, C., Lee, C., Kelly, J., Ahima, R. S., Bjorbæk, C., et al. (1999). Leptin differentially regulates NPY and POMC neurons projecting to the lateral hypothalamic area. Neuron 23, 775-786. doi: 10.1016/S0896-6273(01)80035-0

Elias, C. F., Lee, C., Kelly, J., Aschkenasi, C., Ahima, R. S., Couceyro, P. R., et al. (1998). Leptin activates hypothalamic CART neurons projecting to the spinal cord. Neuron 21, 1375-1385. doi: 10.1016/S0896-6273(00)80656-X

Elias, C. F., Lee, C. E., Kelly, J. F., Ahima, R. S., Kuhar, M., Saper, C. B., et al. (2001). Characterization of CART neurons in the rat and human hypothalamus. J. Comp. Neurol. 432, 1-19. doi: 10.1002/cne.1085

Ellis, L., and Mawe, G. (2003). Distribution and chemical coding of cocaine- and amphetamine-regulated transcript peptide (CART)-immunoreactive neurons 
in the guinea pig bowel. Cell Tissue Res. 312, 265-274. doi: 10.1007/s00441-0020678-9

Elmquist, J. K., Maratos-Flier, E., Saper, C. B., and Flier, J. S. (1998). Unraveling the central nervous system pathways underlying responses to leptin. Nat. Neurosci. 1, 445-450. doi: 10.1038/2164

Fagergren, P., and Hurd, Y. L. (1999). Mesolimbic gender differences in peptide CART mRNA expression: effects of cocaine. Neuroreport 10, 3449-3452. doi: 10.1097/00001756-199911080-00034

Fan, W., Boston, B. A., Kesterson, R. A., Hruby, V. J., and Cone, R. D. (1997). Role of melanocortinergic neurons in feeding and the agouti obesity syndrome. Nature 385, 165-168. doi: 10.1038/385165a0

Faouzi, M., Leshan, R., Björnholm, M., Hennessey, T., Jones, J., and Münzberg, H. (2007). Differential accessibility of circulating leptin to individual hypothalamic sites. Endocrinology 148, 5414-5423. doi: 10.1210/en.2007-0655

Fekete, C., Mihály, E., Luo, L.-G., Kelly, J., Clausen, J. T., Mao, Q., et al. (2000). Association of cocaine- and amphetamine-regulated transcriptimmunoreactive elements with thyrotropin-releasing hormone-synthesizing neurons in the hypothalamic paraventricular nucleus and its role in the regulation of the hypothalamic-pituitary-thyroid axis during fasting. J. Neurosci. 20, 9224-9234.

Fekete, C., Wittmann, G., Liposits, Z., and Lechan, R. M. (2004). Origin of cocaineand amphetamine-regulated transcript (CART)-immunoreactive innervation of the hypothalamic paraventricular nucleus. J. Comp. Neurol. 469, 340-350. doi: 10.1002/cne.10999

Friedman, J. M., and Halaas, J. L. (1998). Leptin and the regulation of body weight in mammals. Nature 395, 763-770. doi: 10.1038/27376

Gautvik, K. M., de Lecea, L., Gautvik, V. T., Danielson, P. E., Tranque, P., Dopazo, A., et al. (1996). Overview of the most prevalent hypothalamus-specific mRNAs, as identified by directional tag PCR subtraction. Proc. Natl. Acad. Sci. U.S.A. 93, 8733-8738. doi: 10.1073/pnas.93.16.8733

Germano, C. M. R., de Castro, M., Rorato, R., Laguna, M. T. C., AntunesRodrigues, J., Elias, C. F., et al. (2007). Time course effects of adrenalectomy and food intake on cocaine- and amphetamine-regulated transcript expression in the hypothalamus. Brain Res. 1166, 55-64. doi: 10.1016/j.brainres.2007.05.077

Gilbert, D. B., and Cooper, S. J. (1995). 7-OH-DPAT injected into the accumbens reduces locomotion and sucrose ingestion: D3 autoreceptor-mediated effects? Pharmacol. Biochem. Behav. 52, 275-280. doi: 10.1016/0091-3057(95) 00113-B

Gozen, O., Balkan, B., Yararbas, G., Koylu, E. O., Kuhar, M. J., and Pogun, S. (2007). Sex differences in the regulation of cocaine and amphetamine-regulated transcript expression in hypothalamic nuclei of rats by forced swim stress. Synapse 61, 561-568. doi: 10.1002/syn.20395

Grayson, B. E., Allen, S. E., Billes, S. K., Williams, S. M., Smith, M. S., and Grove, K. L. (2006). Prenatal development of hypothalamic neuropeptide systems in the nonhuman primate. Neuroscience 143, 975-986. doi: 10.1016/j.neuroscience.2006.08.055

Guerardel, A., Barat-Houari, M., Vasseur, F., Dina, C., Vatin, V., Clement, K., et al. (2005). Analysis of sequence variability in the CART gene in relation to obesity in a Caucasian population. BMC Genet. 6:19. doi: 10.1186/1471-2156-6-19

Hager, J., Dina, C., Francke, S., Dubois, S., Houari, M., Vatin, V., et al. (1998). A genome-wide scan for human obesity genes reveals a major susceptibility locus on chromosome 10. Nat. Genet. 20, 304-308. doi: 10.1038/3123

Heldsinger, A., Lu, Y., Zhou, S.-Y., Wu, X., Grabauskas, G., Song, I., et al. (2012). Cocaine- and amphetamine-regulated transcript is the neurotransmitter regulating the action of cholecystokinin and leptin on short-term satiety in rats. Am. J. Physiol. Gastrointest. Liver. Physiol. 303, G1042-G1051. doi: 10.1152/ajpgi. 00231.2012

Henry, B. A., Rao, A., Ikenasio, B. A., Mountjoy, K. G., Tilbrook, A. J., and Clarke, I. J. (2001). Differential expression of cocaine- and amphetamine-regulated transcript and agouti related-protein in chronically food-restricted sheep. Brain Res. 918, 40-50. doi: 10.1016/S0006-8993(01)02918-3

Holstege, G., Meiners, L., and Tan, K. (1985). Projections of the bed nucleus of the stria terminalis to the mesencephalon, pons, and medulla oblongata in the cat. Exp. Brain Res. 58, 379-391. doi: 10.1007/BF00235319

Hopkins, D. A., and Holstege, G. (1978). Amygdaloid projections to the mesencephalon, pons and medulla oblongata in the cat. Exp. Brain Res. 32, 529-547. doi: 10.1007/BF00239551

Horvath, T. L., Bechmann, I., Naftolin, F., Kalra, S. P., and Leranth, C. (1997). Heterogeneity in the neuropeptide Y-containing neurons of the rat arcuate nucleus: GABAergic and non-GABAergic subpopulations. Brain Res. 756, 283-286. doi: 10.1016/S0006-8993(97)00184-4

Hou, J., Zheng, D.-Z., Zhou, J.-Y., and Zhou, S.-W. (2010). Orexigenic effect of cocaine- and amphetamine-regulated transcript (CART) after injection into hypothalamic nuclei in streptozotocin-diabetic rats. Clin. Exp. Pharmacol. Physiol. 37, 989-995. doi: 10.1111/j.1440-1681.2010.05423.x

Hubert, G. W., and Kuhar, M. J. (2005). Colocalization of CART with substance P but not enkephalin in the rat nucleus accumbens. Brain Res. 1050, 8-14. doi: 10.1016/j.brainres.2005.05.025

Hubert, G. W., and Kuhar, M. J. (2008). Cocaine administration increases the fraction of CART cells in the rat nucleus accumbens that co-immunostain for c-Fos. Neuropeptides 42, 339-343. doi: 10.1016/j.npep.2008.01.001

Hubert, G. W., Manvich, D. F., and Kuhar, M. J. (2010). Cocaine and amphetamineregulated transcript-containing neurons in the nucleus accumbens project to the ventral pallidum in the rat and may inhibit cocaine-induced locomotion. Neuroscience 165, 179-187. doi: 10.1016/j.neuroscience.2009.10.013

Hunter, R., Philpot, K., Vicentic, A., Dominguez, G., Hubert, G., and Kuhar, M. (2004). CART in feeding and obesity. Trends Endocrinol. Metab. 15, 454-459. doi: 10.1016/j.tem.2004.09.010

Hunter, R. G., Bellani, R., Bloss, E., Costa, A., Romeo, R. D., and McEwen, B. S. (2007). Regulation of CART mRNA by stress and corticosteroids in the hippocampus and amygdala. Brain Res. 1152, 234-240. doi: 10.1016/j.brainres.2007.03.042

Huszar, D. (1997). Targeted disruption of the melanocortin-4 receptor results in obesity in mice. Cell 88, 131-141. doi: 10.1016/S0092-8674(00)81865-6

Jaworski, J. N., Hansen, S. T., Kuhar, M. J., and Mark, G. P. (2008). Injection of CART (cocaine- and amphetamine-regulated transcript) peptide into the nucleus accumbens reduces cocaine self-administration in rats. Behav. Brain Res. 191, 266-271. doi: 10.1016/j.bbr.2008.03.039

Jaworski, J. N., Kozel, M. A., Philpot, K. B., and Kuhar, M. J. (2003). Intraaccumbal injection of CART (Cocaine-Amphetamine Regulated Transcript) peptide reduces cocaine-induced locomotor activity. J. Pharmacol. Exp. Ther. 307, 1038-1044. doi: 10.1124/jpet.103.052332

Jean, A., Conductier, G. G., Manrique, C., Bouras, C., Berta, P., Hen, R., et al. (2007). Anorexia induced by activation of serotonin 5-HT4 receptors is mediated by increases in CART in the nucleus accumbens. Proc.e Natl. Acad. Sci. U.S.A. 104, 16335-16340. doi: 10.1073/pnas.0701471104

Jensen, P., Kristensen, P., Clausen, J., Judge, M., Hastrup, S., Thim, L., et al. (1999). The hypothalamic satiety peptide CART is expressed in anorectic and nonanorectic pancreatic islet tumors and in the normal islet of Langerhans. FEBS Lett. 447, 139-143. doi: 10.1016/S0014-5793(99)00291-4

Job, M. O., and Kuhar, M. J. (2012). Intraperitoneal administration of CART 55-102 inhibits psychostimulant-induced locomotion. J. Drug Alcohol Res. 1:235601. doi: $10.4303 /$ jdar/235601

Johansen, J. E., Broberger, C., Lavebratt, C., Johansson, C., Kuhar, M. J., Hökfelt, T., et al. (2000). Hypothalamic CART and serum leptin levels are reduced in the anorectic (anx/anx) mouse. Mol. Brain Res. 84, 97-105. doi: 10.1016/S0169$328 \mathrm{X}(00) 00228-\mathrm{X}$

Kasacka, I., Janiuk, I., Lewandowska, A., Bekisz, A., and Łebkowski, W. (2012). Distribution pattern of CART-containing neurons and cells in the human pancreas. Acta Histochem. 114, 695-699. doi: 10.1016/j.acthis.2011. 12.004

Kask, A., Schiöth, H. B., Mutulis, F., Wikberg, J. E. S., and Rägo, L. (2000). Anorexigenic cocaine- and amphetamine-regulated transcript peptide intensifies fear reactions in rats. Brain Res. 857, 283-285. doi: 10.1016/S00068993(99)02383-5

Kim, J. H., Creekmore, E., and Vezina, P. (2003). Microinjection of CART peptide 55-102 into the nucleus accumbens blocks amphetamine-induced locomotion. Neuropeptides 37, 369-373. doi: 10.1016/j.npep.2003.10.001

Kim, M. S., Rossi, M., Abusnana, S., Sunter, D., Morgan, D. G., Small, C. J., et al. (2000). Hypothalamic localization of the feeding effect of agouti-related peptide and alpha-melanocyte-stimulating hormone. Diabetes 49, 177-182. doi: 10.2337/diabetes.49.2.177

Kong, W. M., Stanley, S., Gardiner, J., Abbott, C., Murphy, K., Seth, A., et al. (2003). A role for arcuate cocaine and amphetamine regulated transcript in hyperphagia, thermogenesis, and cold adaptation. FASEB J. 17, 1688-1690. doi: 10.1096/fj.02-0805fje

Koob, G. F., and Bloom, F. E. (1988). Cellular and molecular mechanisms of drug dependence. Science 242, 715-723. doi: 10.1126/science.2903550 
Koylu, E. O., Couceyro, P. R., Lambert, P. D., and Kuhar, M. J. (1998). Cocaine- and amphetamine-regulated transcript peptide immunohistochemical localization in the rat brain. J. Comp. Neurol. 391, 115-132.

Koylu, E. O., Couceyro, P. R., Lambert, P. D., Ling, N. C., DeSouza, E. B., and Kuhar, M. J. (1997). Immunohistochemical localization of novel CART peptides in rat hypothalamus, pituitary and adrenal gland. J. Neuroendocrinol. 9, 823-833. doi: 10.1046/j.1365-2826.1997.00651.x

Koylu, E. O., Weruaga, E., Balkan, B., Alonso, J. R., Kuhar, M. J., and Pogun, S. (2000). Co-localization of cart peptide immunoreactivity and nitric oxide synthase activity in rat hypothalamus. Brain Res. 868, 352-357. doi: 10.1016/S00068993(00)02290-3

Kristensen, P., Judge, M., Thim, L., Ribel, U., Christjansen, K., Wulff, B., et al. (1998). Hypothalamic CART is a new anorectic peptide regulated by leptin. Nature 393, 72-76. doi: 10.1038/29993

Kuhar, M., Jaworski, J., Hubert, G., Philpot, K., and Dominguez, G. (2005). Cocaine- and amphetamine-regulated transcript peptides play a role in drug abuse and are potential therapeutic targets. AAPS J. 7, E259-E265. doi: 10.1208/aapsj070125

Kuhar, M. J., and Yoho, L. L. (1999). CART peptide analysis by Western blotting. Synapse 33, 163-171.

Lakatos, A., Prinster, S., Vicentic, A., Hall, R. A., and Kuhar, M. J. (2005). Cocaine- and amphetamine-regulated transcript (CART) peptide activates the extracellular signal-regulated kinase (ERK) pathway in AtT20 cells via putative G-protein coupled receptors. Neurosci. Lett. 384, 198-202. doi: 10.1016/j.neulet.2005.04.072

Lambert, P., Couceyro, P., McGirr, K., Dall Vechia, S., Smith, Y., and Kuhar, M. (1998). CART peptides in the central control of feeding and interactions with neuropeptide Y. Synapse 29, 293-298.

Larsen, P. J., Seier, V., Fink-Jensen, A., Holst, J. J., Warberg, J., and Vrang, N. (2003). Cocaine- and amphetamine-regulated transcript is present in hypothalamic neuroendocrine neurones and is released to the hypothalamic-pituitary portal circuit. J. Neuroendocrinol. 15, 219-226. doi: 10.1046/j.1365-2826.2003.00960.x

Larsen, P. J., Vrang, N., Petersen, P. C., and Kristensen, P. (2000). Chronic intracerebroventricular administration of recombinant CART(42-89) peptide inhibits food intake and causes weight loss in lean and obese zucker (fa/fa) rats. Obes. Res. 8, 590-596. doi: 10.1038/oby.2000.76

Li, H.-Y., Hwang, H.-W., and Hu, Y.-H. (2002). Functional characterizations of cocaine- and amphetamine-regulated transcript mRNA expression in rat hypothalamus. Neurosci. Lett. 323, 203-206. doi: 10.1016/S03043940(02)00151-9

Lin, Y., Hall, R. A., and Kuhar, M. J. (2011). CART peptide stimulation of $G$ protein-mediated signaling in differentiated PC12 cells: identification of PACAP 6-38 as a CART receptor antagonist. Neuropeptides 45, 351-358. doi: 10.1016/j.npep.2011.07.006

Lodge, D., and Lawrence, A. (2001). Comparative analysis of the central CCK system in Fawn Hooded and Wistar Kyoto rats: extended localisation of CCK-A receptors throughout the rat brain using a novel radioligand. Regul. Pept. 99, 191-201. doi: 10.1016/S0167-0115(01)00256-7

Ludwig, D. S., Mountjoy, K. G., Tatro, J. B., Gillette, J. A., Frederich, R. C., Flier, J. S., et al. (1998). Melanin-concentrating hormone: a functional melanocortin antagonist in the hypothalamus. Am. J. Physiol. 274, E627-E633.

Maixnerova, J., Hlavcek, J., Blokesova, D., Kowalczyk, W., Elbert, T., Sanda, M., et al. (2007). Structure-activity relationship of CART (cocaine- and amphetamine-regulated transcript) peptide fragments. Peptides 28, 1945-1953. doi: $10.1016 /$ j.peptides.2007.07.022

Maletinska, L., Maixnerova, J., Matyskova, R., Haugvicova, R., Pirnik, Z., Kiss, A., et al. (2008). Synergistic effect of CART (cocaine- and amphetamine-regulated transcript) peptide and cholecystokinin on food intake regulation in lean mice. BMC Neurosci. 9:101. doi: 10.1186/1471-2202-9-101

Maletinska, L., Maixnerova, J., Matyskova, R., Haugvicova, R., Sloncova, E., Elbert, T., et al. (2007). Cocaine- and amphetamine-regulated transcript (CART) peptide specific binding in pheochromocytoma cells PC12. Eur. J. Pharmacol. 559, 109-114. doi: 10.1016/j.ejphar.2006.12.014

Marty, N., Dallaporta, M., and Thorens, B. (2007). Brain glucose sensing, counterregulation, and energy homeostasis. Physiology (Bethesda) 22, 241-251. doi: 10. 1152/physiol.00010.2007

McGregor, G. P., Desaga, J. F., Ehlenz, K., Fischer, A., Heese, F., Hegele, A., et al. (1996). Radiommunological measurement of leptin in plasma of obese and diabetic human subjects. Endocrinology 137, 1501-1504.
Menyhért, J., Wittmann, G., Lechan, R. M., Keller, E., Liposits, Z., and Fekete, C. (2007). Cocaine- and amphetamine-regulated transcript (CART) is colocalized with the orexigenic neuropeptide $\mathrm{Y}$ and agouti-related protein and absent from the anorexigenic $\alpha$-melanocyte-stimulating hormone neurons in the infundibular nucleus of the human hypothalamus. Endocrinology 148, 4276-4281. doi: 10.1210/en.2007-0390

Mercer, L., and Beart, P. (1997). Histochemistry in rat brain and spinal cord with an antibody directed at the cholecystokinin A receptor. Neurosci. Lett. 225, 97-100. doi: 10.1016/S0304-3940(97)00197-3

Merino, B., Cano, V., Guzmán, R. O., Somoza, B., and Ruiz-Gayo, M. (2008). Leptin-mediated hypothalamic pathway of cholecystokinin (CCK-8) to regulate body weight in free-feeding rats. Endocrinology 149, 1994-2000. doi: 10.1210/en.2007-1286

Mihaly, E., Fekete, C., Tatro, J. B., Liposits, Z., Stopa, E. G., and Lechan, R. M. (2000). Hypophysiotropic thyrotropin-releasing hormone-synthesizing neurons in the human hypothalamus are innervated by neuropeptide Y, agoutirelated protein, and $\alpha$-melanocyte-stimulating hormone. J. Clin. Endocrinol. Metab. 85, 2596-2603. doi: 10.1210/jc.85.7.2596

Moffett, M., Stanek, L., Harley, J., Rogge, G., Asnicar, M., Hsiung, H., et al. (2006). Studies of cocaine- and amphetamine-regulated transcript (CART) knockout mice. Peptides 27, 2037-2045. doi: 10.1016/j.peptides.2006.03.035

Moran, T., Ameglio, P., Schwartz, G., and McHugh, P. (1992). Blockade of type A, not type B, CCK receptors attenuates satiety actions of exogenous and endogenous CCK. Am. J. Physiol. 262, R46-R50.

Morton, G., Blevins, J., Williams, D., Niswender, K., Gelling, R., Rhodes, C., et al. (2005). Leptin action in the forebrain regulates the hindbrain response to satiety signals. J. Clin. Invest. 115, 703-710. doi: 10.1172/JCI200522081

Murphy, K., Abbott, C., Mahmoudi, M., Hunter, R., Gardiner, J., Rossi, M., et al. (2000). Quantification and synthesis of cocaine- and amphetamine-regulated transcript peptide (79-102)-like immunoreactivity and mRNA in rat tissues. J. Endocrinol. 166, 659-668. doi: 10.1677/joe.0.1660659

Nakazato, M., Murakami, N., Date, Y., Kojima, M., Matsuo, H., Kangawa, K., et al. (2001). A role for ghrelin in the central regulation of feeding. Nature 409, 194-198. doi: 10.1038/35051587

Nakhate, K. T., Kokare, D. M., Singru, P. S., and Subhedar, N. K. (2011). Central regulation of feeding behavior during social isolation of rat: evidence for the role of endogenous CART system. Int. J. Obes. 35, 773-784. doi: 10.1038/ijo. 2010.231

Nakhate, K. T., Kokare, D. M., Singru, P. S., Taksande, A. G., Kotwal, S. D., and Subhedar, N. K. (2010). Hypothalamic cocaine- and amphetamine-regulated transcript peptide is reduced and fails to modulate feeding behavior in rats with chemically-induced mammary carcinogenesis. Pharmacol. Biochem. Behav. 97, 340-349. doi: 10.1016/j.pbb.2010.09.001

Nakhate, K. T., Subhedar, N. K., Bharne, A. P., Singru, P. S., and Kokare, D. M. (2013). Involvement of cocaine- and amphetamine-regulated transcript peptide in the hyperphagic and body weight promoting effects of allopregnanolone in rats. Brain Res. 1532, 44-55. doi: 10.1016/j.brainres.2013.07.055

Okumura, T., Yamada, H., Motomura, W., and Kohgo, Y. (2000). Cocaineamphetamine-regulated transcript (CART) acts in the central nervous system to inhibit gastric acid secretion via brain corticotropin-releasing factor system. Endocrinology 141, 2854-2860. doi: 10.1210/en.141.8.2854

Osei-Hyiaman, D., Depetrillo, M., Harvey-White, J., Bannon, A. W., Cravatt, B. F., Kuhar, M. J., et al. (2005). Cocaine- and amphetamine-related transcript is involved in the orexigenic effect of endogenous anandamide. Neuroendocrinology 81, 273-282. doi: 10.1159/000087925

Ostlund, R. E., Yang, J. W., Klein, S., and Gingerich, R. (1996). Relation between plasma leptin concentration and body fat, gender, diet, age, and metabolic covariates. J. Clin. Endocrinol. Metab. 81, 3909-3913.

Pang, Z. P., and Han, W. (2012). Regulation of synaptic functions in central nervous system by endocrine hormones and the maintenance of energy homoeostasis. Biosci. Rep. 32, 423-432. doi: 10.1042/BSR20120026

Parker, J. A., and Bloom, S. R. (2012). Hypothalamic neuropeptides and the regulation of appetite. Neuropharmacology 63, 18-30. doi: 10.1016/j.neuropharm.2012.02.004

Peyron, C., Tighe, D. K., van den Pol, A. N., de Lecea, L., Heller, H. C., Sutcliffe, J. G., et al. (1998). Neurons containing hypocretin (Orexin) project to multiple neuronal systems. J. Neurosci. 18, 9996-10015.

Philpot, K., and Smith, Y. (2006). CART peptide and the mesolimbic dopamine system. Peptides 27, 1987-1992. doi: 10.1016/j.peptides.2005.11.028 
Pirnik, Z., Maixnerova, J., Matyskova, R., Koutova, D., Zelezna, B., Maletinska, L., et al. (2010). Effect of anorexinergic peptides, cholecystokinin (CCK) and cocaine and amphetamine regulated transcript (CART) peptide, on the activity of neurons in hypothalamic structures of $\mathrm{C} 57 \mathrm{Bl} / 6$ mice involved in the food intake regulation. Peptides 31, 139-144. doi: 10.1016/j.peptides.2009.09.035

Pothos, E., Creese, I., and Hoebel, B. (1995). Restricted eating with weight loss selectively decreases extracellular dopamine in the nucleus accumbens and alters dopamine response to amphetamine, morphine, and food intake. J. Neurosci. 15, 6640-6650.

Qing, K., and Chen, Y. (2007). Central CART gene delivery by recombinant AAV vector attenuates body weight gain in diet-induced-obese rats. Regul. Pept. 140, 21-26. doi: 10.1016/j.regpep.2006.11.019

Qu, D., Ludwig, D. S., Gammeltoft, S., Piper, M., Pelleymounter, M. A., Cullen, M. J., et al. (1996). A role for melanin-concentrating hormone in the central regulation of feeding behaviour. Nature 380, 243-247. doi: 10.1038/380243a0

Rigoli, L., Munafò, C., Di Bella, C., Salpietro, A., Procopio, V., and Salpietro, C. (2010). Molecular analysis of the CART gene in overweight and obese Italian children using family-based association methods. Acta Paediatr. 99, 722-726. doi: 10.1111/j.1651-2227.2010.01709.x

Rogge, G., Jones, D., Hubert, G. W., Lin, Y., and Kuhar, M. J. (2008). CART peptides: regulators of body weight, reward and other functions. Nat. Rev. Neurosci. 9, 747-758. doi: 10.1038/nrn2493

Rohner-Jeanrenaud, F., Craft, L. S., Bridwell, J., Suter, T. M., Tinsley, F. C., Smiley, D. L., et al. (2002). Chronic central infusion of cocaine- and amphetamineregulated transcript (CART 55-102): effects on body weight homeostasis in lean and high-fat-fed obese rats. Int. J. Obes. Relat. Metab. Disord. 26, 143-149. doi: 10.1038/sj.ijo.0801863

Rossi, M., Choi, S. J., O’Shea, D., Miyoshi, T., Ghatei, M. A., and Bloom, S. R. (1997). Melanin-concentrating hormone acutely stimulates feeding, but chronic administration has no effect on body weight. Endocrinology 138, 351-355. doi: 10.1210/endo.138.1.4887

Sakurai, T., Amemiya, A., Ishii, M., Matsuzaki, I., Chemelli, R. M., Tanaka, H., et al. (1998). Orexins and orexin receptors: a family of hypothalamic neuropeptides and g protein-coupled receptors that regulate feeding behavior. Cell 92, 573-585. doi: 10.1016/S0092-8674(00)80949-6

Salamone, J. D. (1996). The behavioral neurochemistry of motivation: methodological and conceptual issues in studies of the dynamic activity of nucleus accumbens dopamine. J. Neurosci. Methods 64, 137-149. doi: 10.1016/01650270(95)00125-5

Saper, C. B., Chou, T. C., and Elmquist, J. K. (2002). The need to feed: homeostatic and hedonic control of eating. Neuron 36, 199-211. doi: 10.1016/S08966273(02)00969-8

Sarkar, S., Wittmann, G. B., Fekete, C., and Lechan, R. M. (2004). Central administration of cocaine- and amphetamine-regulated transcript increases phosphorylation of CAMP response element binding protein in corticotropin-releasing hormone-producing neurons but not in prothyrotropin-releasing hormoneproducing neurons in the hypothalamic paraventricular nucleus. Brain Res. 999, 181-192. doi: 10.1016/j.brainres.2003.11.062

Schwartz, M. W., Woods, S. C., Porte, D., Seeley, R. J., and Baskin, D. G. (2000). Central nervous system control of food intake. Nature 404, 661-671. doi: 10. 1038/35007534

Seidah, N. G., Marcinkiewicz, M., Benjannet, S., Gaspar, L., Beaubien, G., Mattei, M. G., et al. (1991). Cloning and primary sequence of a mouse candidate prohormone convertase PC1 homologous to PC2, furin, and Kex2: distinct chromosomal localization and messenger RNA distribution in brain and pituitary compared to PC2. Mol. Endocrinol. 5, 111-122. doi: 10.1210/mend-5-1-111

Sen, A., Bettegowda, A., Jimenez-Krassel, F., Ireland, J. J., and Smith, G. W. (2007). Cocaine- and amphetamine-regulated transcript regulation of follicle-stimulating hormone signal transduction in bovine granulosa cells. Endocrinology 148, 4400-4410. doi: 10.1210/en.2007-0332

Shimada, M., Tritos, N. A., Lowell, B. B., Flier, J. S., and Maratos-Flier, E. (1998). Mice lacking melanin-concentrating hormone are hypophagic and lean. Nature 396, 670-674. doi: 10.1038/25341

Skibicka, K. P., Alhadeff, A. L., and Grill, H. J. (2009). Hindbrain cocaineand amphetamine-regulated transcript induces hypothermia mediated by GLP-1 receptors. J. Neurosci. 29, 6973-6981. doi: 10.1523/JNEUROSCI.614408.2009

Smedh, U., and Moran, T. H. (2003). Separable mechanisms for dorsal hindbrain CART peptide to inhibit gastric emptying and food intake. Am. J. Physiol. Regul.
Integr. Comp. Physiol. Regul. Integr. Comp. Physiol. 284, R1418-R1426. doi: 10. 1152/ajpregu.00665.2002

Smedh, U., and Moran, T. H. (2006). The dorsal vagal complex as a site for cocaine- and amphetamine-regulated transcript peptide to suppress gastric emptying. Am. J. Physiol. Regul. Integr. Comp. Physiol. 291, R124-R130. doi: 10.1152/ajpregu.00234.2004

Smith, K. L., Gardiner, J. V., Ward, H. L., Kong, W. M., Murphy, K. G., Martin, N. M., et al. (2008). Overexpression of CART in the PVN increases food intake and weight gain in rats. Obesity 16, 2239-2244. doi: 10.1038/oby.2008.366

Smith, O. A., and DeVito, J. L. (1984). Central neural integration for the control of autonomic responses associated with emotion. Annu. Rev. Neurosci. 7, 43-65. doi: 10.1146/annurev.ne.07.030184.000355

Smith, S. M., Vaughan, J. M., Donaldson, C. J., Rivier, J., Li, C., Chen, A., et al. (2004). Cocaine- and amphetamine-regulated transcript activates the hypothalamic-pituitary-adrenal axis through a corticotropin-releasing factor receptor-dependent mechanism. Endocrinology 145, 5202-5209. doi: 10.1210/en.2004-0708

Smith, Y., Kieval, J., Couceyro, P. R., and Kuhar, M. J. (1999). CART peptideimmunoreactive neurones in the nucleus accumbens in monkeys: ultrastructural analysis, colocalization studies, and synaptic interactions with dopaminergic afferents. J. Comp. Neurol. 407, 491-511.

Spiess, J., Villarreal, J., and Vale, W. (1981). Isolation and sequence analysis of a somatostatin-like polypeptide from ovine hypothalamus. Biochemistry 20, 1982-1988. doi: 10.1021/bi00510a038

Stanley, S. A., Murphy, K. G., Bewick, G. A., Kong, W. M., Opacka-Juffry, J., Gardiner, J. V., et al. (2004). Regulation of rat pituitary cocaine- and amphetamine-regulated transcript (CART) by CRH and glucocorticoids. Am. J. Physiol. Endocrinol. Metab. 287, E583-E590. doi: 10.1152/ajpendo.00576.2003

Stanley, S. A., Small, C. J., Murphy, K. G., Rayes, E., Abbott, C. R., Seal, L. J., et al. (2001). Actions of cocaine- and amphetamine-regulated transcript (CART) peptide on regulation of appetite and hypothalamo-pituitary axes in vitro and in vivo in male rats. Brain Res. 893, 186-194. doi: 10.1016/S00068993(00)03312-6

Stein, J., Shah, R., Steiner, D. F., and Dey, A. (2006). RNAi-mediated silencing of prohormone convertase (PC) 5/6 expression leads to impairment in processing of cocaine- and amphetamine-regulated transcript (CART) precursor. Biochem. J. 400, 209-215. doi: 10.1042/BJ20060506

Steiner, D. F. (1998). The proprotein convertases. Curr. Opin. Chem. Biol. 2, 31-39. doi: 10.1016/S1367-5931(98)80033-1

Steiner, R. C., Hsiung, H. M., and Picciotto, M. R. (2006). Cocaine selfadministration and locomotor sensitization are not altered in CART knockout mice. Behav. Brain Res. 171, 56-62. doi: 10.1016/j.bbr.2006.03.022

Stratford, T. R., Holahan, M. R., and Kelley, A. E. (1997). Injections of nociceptin into nucleus accumbens shell or ventromedial hypothalamic nucleus increase food intake. Neuroreport 8, 423-426. doi: 10.1097/00001756-199701200-00009

Stratford, T. R., and Kelley, A. E. (1999). Evidence of a functional relationship between the nucleus accumbens shell and lateral hypothalamus subserving the control oil feeding behavior. J. Neurosci. 19, 11040-11048.

Subhedar, N. K., Nakhate, K. T., Upadhya, M. A., and Kokare, D. M. (2014). CART in the brain of vertebrates: circuits, functions and evolution. Peptides 54, 108-130. doi: 10.1016/j.peptides.2014.01.004

Tachibana, T., Takagi, T., Tomonaga, S., Ohgushi, A., Ando, R., Denbow, D. M., et al. (2003). Central administration of cocaine- and amphetamine-regulated transcript inhibits food intake in chicks. Neurosci. Lett. 337, 131-134. doi: 10.1016/S0304-3940(02)01321-6

Tebbe, J. J., Mronga, S., Schäfer, M. K.-H., Rüter, J., Kobelt, P., and Mönnikes, H. (2003). Stimulation of neurons in rat ARC inhibits gastric acid secretion via hypothalamic CRF1/2- and NPY-Y1 receptors. Am. J. Physiol. Gastrointest. Liver Physiol. 285, G1075-G1083. doi: 10.1152/ajpgi.00125.2003

Tebbe, J. J., Ortmann, E., Schumacher, K., Mönnikes, H., Kobelt, P., Arnold, R., et al. (2004). Cocaine- and amphetamine-regulated transcript stimulates colonic motility via central CRF receptor activation and peripheral cholinergic pathways in fed, conscious rats. Neurogastroenterol. Motil. 16, 489-496. doi: 10.1111/j.1365-2982.2004.00561.x

Thim, L., Kristensen, P., Nielsen, P., Wulff, B., and Clausen, J. (1999). Tissue-specific processing of cocaine- and amphetamine-regulated transcript peptides in the rat. Proc. Natl. Acad. Sci. U.S.A. 96, 2722-2727. doi: 10.1073/pnas.96.6.2722

Thim, L., Nielsen, P. F., Judge, M. E., Andersen, A. S., Diers, I., Egel-Mitani, M., et al. (1998). Purification and characterisation of a new hypothalamic satiety 
peptide, cocaine and amphetamine regulated transcript (CART), produced in yeast. FEBS Lett. 428, 263-268. doi: 10.1016/S0014-5793(98)00543-2

Upadhya, M. A., Nakhate, K. T., Kokare, D. M., Singh, U., Singru, P. S., and Subhedar, N. K. (2012). CART peptide in the nucleus accumbens shell acts downstream to dopamine and mediates the reward and reinforcement actions of morphine. Neuropharmacology 62, 1823-1833. doi: 10.1016/j.neuropharm.2011.12.004

VanElzakker, M., Fevurly, R. D., Breindel, T., and Spencer, R. L. (2008). Environmental novelty is associated with a selective increase in Fos expression in the output elements of the hippocampal formation and the perirhinal cortex. Learn. Mem. 15, 899-908. doi: 10.1101/lm.1196508

Van Vugt, D. A., Lujan, M. E., Froats, M., Krzemien, A., Couceyro, P. R., and Reid, R. L. (2006). Effect of fasting on cocaine-amphetamine-regulated transcript, neuropeptide $\mathrm{Y}$, and leptin receptor expression in the non-human primate hypothalamus. Neuroendocrinology 84, 83-93. doi: 10.1159/000097494

Vasseur, F., Guérardel, A., Barat-Houari, M., Cottel, D., Amouyel, P., Froguel, P., et al. (2007). Impact of a CART promoter genetic variation on plasma lipid profile in a general population. Mol. Genet. Metab. 90, 199-204. doi: 10.1016/j.ymgme.2006.08.012

Vicentic, A. (2006). CART peptide diurnal variations in blood and brain. Peptides 27, 1942-1948. doi: 10.1016/j.peptides.2006.01.026

Volkoff, H. (2006). The role of neuropeptide Y, orexins, cocaine and amphetaminerelated transcript, cholecystokinin, amylin and leptin in the regulation of feeding in fish. Comp. Biochem. Physiol. A Mol. Integr. Physiol. 144, 325-331. doi: 10.1016/j.cbpa.2005.10.026

Volkoff, H., and Peter, R. E. (2000). Effects of CART peptides on food consumption, feeding and associated behaviors in the goldfish, Carassius auratus: actions on neuropeptide Y- and orexin A-induced feeding. Brain Res. 887, 125-133. doi: 10.1016/S0006-8993(00)03001-8

Vong, L., Ye, C., Yang, Z., Choi, B., Chua, S. Jr., and Lowell, B. B. (2011). Leptin action on GABAergic neurons prevents obesity and reduces inhibitory tone to POMC neurons. Neuron 71, 142-154. doi: 10.1016/j.neuron.2011.05.028

Vrang, N. (2006). Anatomy of hypothalamic CART neurons. Peptides 27, 1970-1980. doi: 10.1016/j.peptides.2005.10.029

Vrang, N., Larsen, P. J., Clausen, J. T., and Kristensen, P. (1999a). Neurochemical characterization of hypothalamic cocaine-amphetamine-regulated transcript neurons. J. Neurosci. 19, RC5.

Vrang, N., Larsen, P. J., Kristensen, P., and Tang-Christensen, M. (2000). Central administration of cocaine-amphetamine-regulated transcript activates hypothalamic neuroendocrine neurons in the rat. Endocrinology 141, 794-801. doi: 10.1210/endo.141.2.7295

Vrang, N., Larsen, P. J., Tang-Christensen, M., Larsen, L. K., and Kristensen, P. (2003). Hypothalamic cocaine-amphetamine regulated transcript (CART) is regulated by glucocorticoids. Brain Res. 965, 45-50. doi: 10.1016/S00068993(02)04064-7

Vrang, N., Tang-Christensen, M., Larsen, P., and Kristensen, P. (1999b). Recombinant CART peptide induces c-Fos expression in central areas involved in control of feeding behaviour. Brain Res. 818, 499-509. doi: 10.1016/S00068993(98)01349-3

Walder, K., Morris, C., and Ravussin, E. (2000). A polymorphism in the gene encoding CART is not associated with obesity in Pima Indians. Int. J. Obes. Relat. Metab. Disord. 24, 520-521. doi: 10.1038/sj.ijo.0801196

Wang, C. F., Billington, C. J., Levine, A. S., and Kotz, C. M. (2000). Effect of CART in the hypothalamic paraventricular nucleus on feeding and uncoupling protein gene expression. Neuroreport 11, 3251-3255. doi: 10.1097/00001756200009280-00040

Wang, Z.-W., Zhou, Y.-T., Kakuma, T., Lee, Y., Higa, M., Kalra, S. P., et al. (1999). Comparing the hypothalamic and extrahypothalamic actions of endogenous hyperleptinemia. Proc. Natl. Acad. Sci. U.S.A. 96, 10373-10378. doi: 10.1073/pnas.96.18.10373

Wierup, N., Björkqvist, M., Kuhar, M. J., Mulder, H., and Sundler, F. (2006). CART regulates islet hormone secretion and is expressed in the $\beta$-cells of type 2 diabetic rats. Diabetes 55, 305-311. doi: 10.2337/diabetes.55.02.06.db 04-1383

Wierup, N., Gunnarsdottir, A., Ekblad, E., and Sundler, F. (2007). Characterisation of CART-containing neurons and cells in the porcine pancreas, gastro-intestinal tract, adrenal and thyroid glands. BMC Neurosci. 8:51. doi: 10.1186/14712202-8-51

Wierup, N., Kuhar, M., Nilsson, B., Mulder, H., Ekblad, E., and Sundler, F. (2004). Cocaine- and amphetamine- regulated transcript (CART) is expressed in several islet cell types during rat development. J. Histochem. Cytochem. 52, 169. doi: 10.1177/002215540405200204

Wierup, N., Richards, W., Bannon, A., Kuhar, M., Ahren, B., and Sundler, F. (2005). CART knock out mice have impaired insulin secretion and glucose intolerance, altered beta cell morphology and increased body weight. Regul. Pept. 129, 203-211. doi: 10.1016/j.regpep.2005.02.016

Williams, G., Bing, C., Cai, X. J., Harrold, J. A., King, P. J., and Liu, X. H. (2001). The hypothalamus and the control of energy homeostasis: different circuits, different purposes. Physiol. Behav. 74, 683-701. doi: 10.1016/S0031-9384(01)00612-6

Wortley, K. E., Chang, G.-Q., Davydova, Z., Fried, S. K., and Leibowitz, S. F. (2004). Cocaine- and amphetamine-regulated transcript in the arcuate nucleus stimulates lipid metabolism to control body fat accrual on a high-fat diet. Regul. Pept. 117, 89-99. doi: 10.1016/j.regpep.2003.08.005

Yamada, K., Yuan, X., Otabe, S., Koyanagi, A., Koyama, W., and Makita, Z. (2002). Sequencing of the putative promoter region of the cocaine- and amphetamineregulated-transcript gene and identification of polymorphic sites associated with obesity. Int. J. Obes. 26, 132-136. doi: 10.1038/sj.ijo.0801848

Yang, S.-C., and Shieh, K.-R. (2005). Differential effects of melanin concentrating hormone on the central dopaminergic neurons induced by the cocaineand amphetamine-regulated transcript peptide. J. Neurochem. 92, 637-646. doi: 10.1111/j.1471-4159.2004.02896.x

Yang, S. C., Shieh, K. R., and Li, H. Y. (2005). Cocaine- and amphetamineregulated transcript in the nucleus accumbens participates in the regulation of feeding behavior in rats. Neuroscience 133, 841-851. doi: 10.1016/j.neuroscience.2005.03.023

Yanik, T., Dominguez, G., Kuhar, M. J., Del Giudice, E. M., and Loh, Y. P. (2006). The Leu34Phe ProCART mutation leads to cocaine- and amphetamineregulated transcript (CART) deficiency: a possible cause for obesity in humans. Endocrinology 147, 39-43. doi: 10.1210/en.2005-0812

Yermolaieva, O., Chen, J., Couceyro, P. R., and Hoshi, T. (2001). Cocaine- and amphetamine-regulated transcript peptide modulation of voltage-gated $\mathrm{Ca}^{2+}$ signaling in hippocampal neurons. J. Neurosci. 21, 7474-7480.

Zhang, M., Han, L., and Xu, Y. (2012). Roles of cocaine- and amphetamineregulated transcript in the central nervous system. Clin. Exp. Pharmacol. Physiol. 39, 586-592. doi: 10.1111/j.1440-1681.2011.05642.x

Zhang, Y., Proenca, R., Maffei, M., Barone, M., Leopold, L., and Friedman, J. M. (1994). Positional cloning of the mouse obese gene and its human homologue. Nature 372, 425-432. doi: 10.1038/372425a0

Zheng, H., Corkern, M., Stoyanova, I., Patterson, L. M., Tian, R., and Berthoud, H.-R. (2003). Peptides that regulate food intake: appetite-inducing accumbens manipulation activates hypothalamic orexin neurons and inhibits POMC neurons. Am. J. Physiol. Regul. Integr. Comp. Physiol. 284, R1436-R1444. doi: 10. 1152/ajpregu.00781.2002

Zheng, H., Patterson, C., and Berthoud, H.-R. (2001). Fourth ventricular injection of CART peptide inhibits short-term sucrose intake in rats. Brain Res. 896, 153-156. doi: 10.1016/S0006-8993(00)03256-X

Zheng, H., Patterson, L., and Berthoud, H.-R. (2002). CART in the dorsal vagal complex: sources of immunoreactivity and effects on Fos expression and food intake. Brain Res. 957, 298-310. doi: 10.1016/S0006-8993(02)03640-5

Zheng, H., Patterson, L. M., Phifer, C. B., and Berthoud, H.-R. (2005). Brain stem melanocortinergic modulation of meal size and identification of hypothalamic POMC projections. Am. J. Physiol. Regul. Integr. Comp. Physiol. 289, R247-R258. doi: 10.1152/ajpregu.00869.2004

Conflict of Interest Statement: The authors declare that the research was conducted in the absence of any commercial or financial relationships that could be construed as a potential conflict of interest.

Received: 01 July 2014; accepted: 17 September 2014; published online: 13 October 2014.

Citation: Lau J and Herzog H (2014) CART in the regulation of appetite and energy homeostasis. Front. Neurosci. 8:313. doi: 10.3389/fnins.2014.00313

This article was submitted to Neuroendocrine Science, a section of the journal Frontiers in Neuroscience.

Copyright (c) 2014 Lau and Herzog. This is an open-access article distributed under the terms of the Creative Commons Attribution License (CC BY). The use, distribution or reproduction in other forums is permitted, provided the original author(s) or licensor are credited and that the original publication in this journal is cited, in accordance with accepted academic practice. No use, distribution or reproduction is permitted which does not comply with these terms. 